\title{
An insight into curcumin-based photosensitization as a promising and green food preservation technology
}

\author{
Maral Seidi Damyeh ${ }^{1}$ (1) ～$\quad$ Ram Mereddy $^{2} \quad \mid \quad$ Michael E. Netzel $^{1} \quad \mid \quad$ Yasmina Sultanbawa $^{1}$ (b)
}

${ }^{1}$ Queensland Alliance for Agriculture and Food Innovation (QAAFI), The University of Queensland, Coopers Plains, QLD, Australia ${ }^{2}$ Department of Agriculture and Fisheries, Queensland Government, Coopers Plains, QLD, Australia

\section{Correspondence}

Y. Sultanbawa, Queensland Alliance for Agricultural and Food Innovation (QAAFI), The University of Queensland, 39 Kessels Road, Coopers Plains, QLD 4108, Australia. Email: y.sultanbawa@uq.edu.au

Funding information Horticulture Australia Limited, Grant/Award Number: HN15001 Naturally Nutritious project

\begin{abstract}
Consumer awareness on the side effects of chemical preservatives has increased the demand for natural preservation technologies. An efficient and sustainable alternative to current conventional preservation techniques should guarantee food safety and retain its quality with minimal side effects. Photosensitization, utilizing light and a natural photosensitizer, has been postulated as a viable and green alternative to the current conventional preservation techniques. The potential of curcumin as a natural photosensitizer is reviewed in this paper as a practical guide to develop a safe and effective decontamination tool for industrial use. The fundamentals of the photosensitization mechanism are discussed, with the main emphasis on the natural photosensitizer, curcumin, and its application to inactivate microorganisms as well as to enhance the shelf life of foods. Photosensitization has shown promising results in inactivating a wide spectrum of microorganisms with no reported microbial resistance due to its particular lethal mode of targeting nucleic acids. Curcumin as a natural photosensitizer has recently been investigated and demonstrated efficacy in decontamination and delaying spoilage. Moreover, studies have shown the beneficial impact of an appropriate encapsulation technique to enhance the cellular uptake of photosensitizers, and therefore, the phototoxicity. Further studies relating to improved delivery of natural photosensitizers with inherent poor solubility should be conducted. Also, detailed studies on various food products are warranted to better understand the impact of encapsulation on curcumin photophysical properties, photodriven release mechanism, and nutritional and organoleptic properties of treated foods.
\end{abstract}

\section{K E Y W O R D S}

curcumin, food preservation, green technology, photosensitization

\section{1 | INTRODUCTION}

Despite introducing a wide range of preservation techniques to the agro-food sector, there are still some pivotal issues regarding their applicability in today's world. This is mostly influenced by the factors such as energy consumption, being environmentally friendly, sustainability, cost-effectiveness, as well as being feasible at farm level.
Fresh fruits and vegetables, for example, get spoiled within a few days due to high perishability, if not treated properly, and resulting in huge industrial losses (almost 45\% loss in grown produce globally [FAO, 2016]). Moreover, the fresh food market is facing challenges with new antibioticresistant microorganisms and insects (new weevils) in the environment, for which the existing decontamination techniques are not efficient. Preservation technologies such as 
ultraviolet light (UV) and pulsed electric field have some crucial drawbacks including safety concerns toward the food handlers (e.g., skin and eye hazards while being exposed to UV), high investment costs, and unacceptable changes in the product quality, in particular sensorial properties. Furthermore, microbial resistance to the nonthermal technologies such as UV, pulsed electric field, and ultrasonication have been reported (Cebrián, Mañas, \& Condón, 2016), which, in turn, reinforce the urgent need for a more efficient alternative.

Photosensitization, also known as photodynamic treatment, has recently gained interest in food research with reported promising results in food systems including significant inactivation of planktonic cells and biofilm of Vibrio parahaemolyticus (Chen et al., 2020), and effective decontamination of pieces of beef, pork, chicken, and apple inoculated with Escherichia coli and Staphylococcus aureus (Corrêa et al., 2020). In fact, no microbial resistance has been reported for photosensitization showing lethal effect on vegetative cells, spores, and biofilms with no harmful effect on surroundings (Luksienè \& Zukauskas, 2009). This is attributed to its multitargeted approach, which can attack lipids, proteins, and nucleic acids simultaneously (Luksiene \& Brovko, 2013). Since ancient times, the combination of sunlight with selected natural extracts has been employed to cure specific skin disorders. However, this phenomenon was scientifically discovered by Oscar Raab (student of Professor von Tappeiner in Munich, Germany) over a hundred years ago, while applying acridine orange (a harmless dye) on paramecia cells (Jori, Camerin, Soncin, Guidolin, \& Coppellotti, 2011).

Advantages of photosensitization over other existing antimicrobial techniques include being efficient and costeffective, reproducible, easy to maintain, safe, nonmutagenic, noncarcinogenic, and environmentally friendly "green" (Luksiene \& Brovko, 2013). However, the main disadvantage of this technique is its inability to penetrate the food exterior layer, and therefore, is more applicable for surface disinfection of foods, food packaging, or food facilities. To a great extent, this technique opens new "roads" to the food industry to not only disinfect the product safely, but also to preserve the quality attributes of the treated food products. The focus of this review is on the photosensitization mechanism and the potential of this innovative technique for the food industry, with a review of indexed literature referring to curcumin as a naturally occurring photosensitizer to substitute harmful disinfectants that are currently used in the food industry. This includes a critical assessment of reported food applications of curcuminbased photosensitization to inactivate microorganisms in food systems.

\section{2 | PHOTOSENSITIZATION MECHANISM}

Generally, the cytotoxic singlet oxygen $\left({ }^{1} \mathrm{O}_{2}\right)$ is produced through the simple and controllable photosensitization process having three main components with nontoxic nature, namely, photosensitizer, light, and oxygen (DeRosa \& Crutchley, 2002). The mechanism is illustrated in the Jablonski diagram (Figure 1). The photosensitizer at its ground state $\left(S_{0}\right)$ absorbs the light at the required wavelength $\left(\lambda_{\max }\right)$. It is then prompted to the unstable singlet excited state $\left(S_{n}\right)$ with a halflife of $10^{-6}$ to $10^{-9} \mathrm{~s}$, through a one-photon transition $(\mathrm{hv})$ (DeRosa \& Crutchley, 2002). A longer half-life is observed for the triplet state of photosensitizer, as it has a lower energy level than the singlet state (Lyon, Moreira, de Moraes, dos Santos, \& de Resende, 2011). Accordingly, relaxation of $S_{n}$ may occur through either emitting fluorescence while returning back to the ground state $\left(S_{0}\right)$ or generating photosensitizer triplet state $\left(T_{1}\right)$ through intersystem crossing. The produced $T_{1}$ reacts via either type I or type II mechanisms due to its longer lifetime ( $\mu \mathrm{s}$ ) compared to $S_{n}$ (ns) (DeRosa $\&$ Crutchley, 2002). Hydrogen atom abstraction or electron transfer between a substrate and the excited photosensitizer occurs during type I mechanism. Here, free radicals are produced from excited photosensitizers by transferring electrons to oxygen followed by reduction in order to generate reactive oxygen species (e.g., superoxide anion, hydrogen peroxide, and hydroxyl radicals) (DeRosa \& Crutchley, 2002). Cellular damage, particularly to its lipophilic components, is a direct result of the produced free radicals (D'Souza, Yuk, Khoo, \& Zhou, 2015). On the other hand, the excited photosensitizer collides with ground state molecular oxygen in type II mechanism, which is also known as photodynamic reaction, and transferring its energy to oxygen resulting in highly reactive singlet oxygen generation. In fact, type II mechanism is more commonly encountered with plant photosensitizers, in which the produced singlet oxygen leads to the required cytotoxicity of the photosensitization process. This is due to the highly efficient interaction of ${ }^{1} \mathrm{O}_{2}$ species with different biomolecules (Luby, Walsh, \& Zheng, 2018). Therefore, a variety of cytotoxic compounds would be produced that give rise to damages to DNA, cell membrane, and various enzymes (D'Souza et al., 2015). Some photosensitizers, such as furanocoumarins, may be able to undergo both pathways (Hudson $\&$ Towers, 1991).

The produced reactive oxygen species by either mechanism cause oxidative damage nonspecifically to multitargets in close proximity of the cell (e.g., cell wall and cell membrane) or even intracellularly (e.g., peptides and nucleic acids) (Haukvik, Bruzell, Kristensen, \& Tønnesen, 2009; Wainwright \& Crossley, 2004). To be more precise, the produced reactive oxygen species oxidize the lipids present in the cell membrane, in particular the unsaturated fatty acids, leading to 


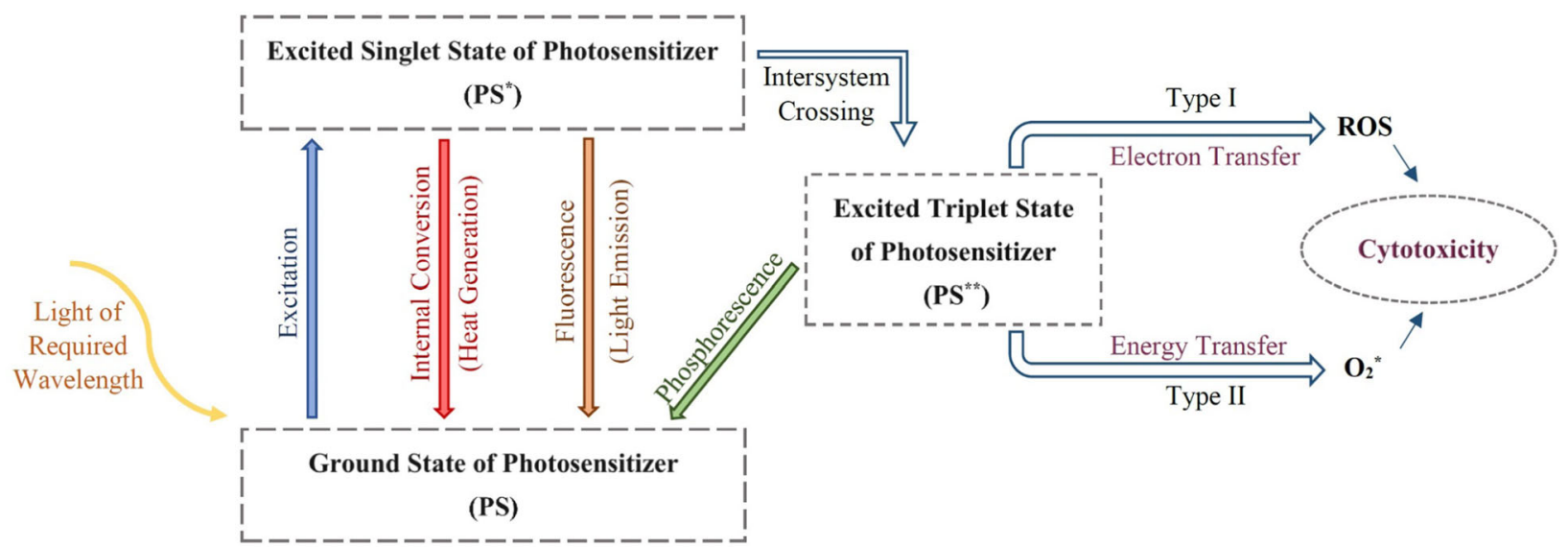

F I G U R E 1 Jablonski diagram, a schematic overview of the photosensitization process

membrane fluidity reduction and therefore membrane-bound proteins disruption (Català, Sumalla, \& Ros Salvador, 2000). This, in turn, gives rise to apoptosis, necrosis, or putrefaction, ending up in cell destruction and death (Kudinova \& Berezov, 2009; Sperandio, Huang, \& Hamblin, 2013). Consequently, direct damage to essential biomolecules required for cellular integrity and function occurs, such as peptide damage through oxidation of amino acids (Bonnett, 1995), and nucleic acid damage through oxidation of guanine bases leading to formation of 8-hydroxyguanosine (Kim, Bang, \& Yuk, 2017; Tuite \& Kelly, 1993). This particular lethal mode of action causes little or no selectivity within the microbial cell, as is demonstrated by the observed sensitivity of three problematic clinical bacteria to photosensitization, namely, S. aureus, Deinococcus radiodurans, and Acinetobacter baumannii (Nitzan \& Ashkenazi, 1999). It is noteworthy to mention that to achieve destruction of cytoplasmic structures as well as inhibition of DNA and RNA synthesis, prolonged illumination is needed, in which no mutagenicity or genotoxicity has been detected (Jori et al., 2011).

One of the important aspects of photosensitization as an antimicrobial technique is its effectiveness against a wide range of microorganisms including parasitic protozoa, mammalian viruses and bacteriophages, fungi, Gram-positive and Gram-negative bacteria in vegetative form, spores, and biofilms (Brovko, 2010). However, due to the differences in cellular structure and cell size, susceptibility of microorganisms to photodynamic treatments is different (Lyon et al., 2011), such as higher resistance of fungi to photodecontamination than bacteria and viruses (Wainwright \& Crossley, 2004). Also, the dual activity of being bactericidal through illumination as well as causing damage to noncellular biomolecules such as extracellular polymeric substance of a bacterial biofilm is considered as a significant advantage of photodisinfection compared to conventional antibacterials (Wainwright \& Crossley, 2004). This critical effect was estab- lished against Pseudomonas aeruginosa biofilm using phenothiazinium as photosensitizer (Wainwright, Phoenix, Nickson, \& Morton, 2002).

Visible light with less microbial inactivation efficacy, compared to other light-based technologies, is gaining more interest in the food safety area. This is due to the possible harmful impacts of UV and pulsed light processing on personnel health and the quality of treated food (Ghate et al., 2017; Kim et al., 2017). The decontamination effect of visible light illumination is through generation of reactive oxygen species from intercellular photosensitizers (Luksienè \& Zukauskas, 2009). Furthermore, higher microbial inactivation efficacy has been reported for the blue region (400 to $500 \mathrm{~nm}$ ), compared to other regions of visible light (Ghate et al., 2013). However, to minimize the blue light processing time and to enhance the magnitude of inactivation, the idea of adding a natural exogenous photosensitizer such as curcumin, with the highest absorbance falling in the blue region, has been put forward. Using visible light illumination only requires a prolonged exposure time to achieve an acceptable microbial inactivation.

\section{3 | PHOTOSENSITIZER}

In general, a chemical component with the ability to absorb a sufficient amount of photons and be excited to a new electronic state is known as photosensitizer, which can react with itself or a second type of molecule. Oxygen is frequently the second type of molecule in biological systems that converts to reactive oxygen species (e.g., singlet oxygen) (Tan et al., 2013). In traditional medicine, some plants have been used in the presence of sunlight to treat some diseases particularly skin diseases such as psoriasis and vitiligo. In Chinese medicine, these diseases were treated by Ammi majus extract containing psoralens and furanochromones, 
TA B L E 1 Examples of investigated natural photosensitizers

\begin{tabular}{lc} 
Photosensitizer & Reference \\
$\begin{array}{l}\text { Microbial intercellular components, for example, cytochromes, porphyrins, } \\
\text { nicotinamide adenine dinucleotide, flavins }\end{array}$ & (Lubart, Lipovski, Nitzan, \& Friedmann, 2011) \\
$\begin{array}{l}\text { Polyketides, for example, thiophenes, quinones, chromenes, polyyines, polyacetylenes } \\
\text { (such as phenylheptatriyne found in the leaves of Bidens spp. and Coreopsis spp.) }\end{array}$ & $\begin{array}{c}\text { (Camm, Towers, \& Mitchell, 1975; Choe \& Min, } \\
\text { 2009; Hudson \& Towers, 1991; Luksiene \& } \\
\text { Brovko, 2013) }\end{array}$ \\
$\begin{array}{l}\text { Cinnamate derivatives, for example, coumarins, furanocoumarins (such as bergapten } \\
\text { [5-methoxypsoralen], xanthotoxin, psoralen, and angelicin) }\end{array}$ & \\
$\begin{array}{l}\text { Alkaloids based on tryptamine, for example, harmane } \\
\text { Phenylalanine and tyrosine, for example, berberine, sanguinarine }\end{array}$ & \\
\hline $\begin{array}{l}\text { Anthranilic acid, for example, furanoquinolines } \\
\text { Protein-based compounds, for example, green fluorescent protein family, the protein } \\
\text { "killer RED," flavoprotein, Zinc-substituted myoglobin }\end{array}$ & (Delcanale et al., 2016; Jiménez-Banzo et al., \\
& 2010; Pimenta, Jensen, Breitenbach, Etzerodt, \\
\& Ogilby, 2013; Vegh et al., 2011)
\end{tabular}

and Hypocrella bambusae extract containing hypocrellin (Yip, Hudson, Gruszecka-Kowalik, Zalkow, \& Towers, 1996).

There are a variety of natural bioactive components found in foods of plant or animal origin that can serve as a photosensitizer. The plant originated ones are known as defense mechanism agents against insect pests (Arnason et al., 1992). Since the advent of photosensitization technique, synthetic dyes have been used as photosensitizers. Red anthraquinone derivatives, hypericin, and pseudohypericin were the very first known natural photosensitizers, which are found in the glands of flowers, leaves, and stems of Hypericum perforaturn (Guttiferae) known as St John's wort, as well as several other species of this genus (Giese, 1980). Photosensitizers can also be considered as antimicrobial agents even if there is no illumination, which can be described as dark activity of agents; however, some may not show any activity in the absence of light (Lacey \& Phillips, 2001). A wide variety of natural photosensitizers have been investigated, some of which are presented in Table 1.

It should be noted that photosensitizers with different structures but same mode of action can be present simultaneously in a given plant species. For example, co-occurrence of polyyines and chromenes in some Asteraceous species (e.g., Encelia), skimmianine (a furanoquinoline) and xanthotoxin (a furanocoumarin) in the leaves of Skimmia japonica (Rutaceae), visnagin and khellin (furanochromones), and psoralen in Psoralea coryifoloia (Fabaceae) (Hudson \& Towers, 1991). Furthermore, being photoactive is not necessarily dependent on the maximum absorbance, but the chemical structure and characteristics of the investigated component are of importance as well. For example, there are some thiophenes related to $\alpha$-terthienyl with similar absorbance within the UV spectrum but no observed photoactivity (Hudson \& Towers, 1991). Overall, aromatic molecules showed to be the common photosensitizers able to produce long-lasting reactive species (Wood \& Bruhn, 2000), such as those containing tetrapyrrole nucleus including bacteriochlorins, porphyrins, phthalocyanines, chlorines, and texaphyrins (Demidova \& Hamblin, 2004).

\section{1 | Important characteristics of photosensitizers}

A large body of evidence demonstrates the significant impact of different factors on the efficacy of photosensitization treatment. With regard to the photosensitizer, there are various important criteria such as its concentration (Spikes, $1989)$, quantum yield ( $\Phi_{\Delta}$, ability to produce singlet oxygen; $\Phi_{T}>0.4$ ) (DeRosa \& Crutchley, 2002), half-life of triplet excited state $\left(\tau_{T}>1 \mu \mathrm{s}\right)$ (Lukšiene, 2005), affinity for target cell (i.e., intracellular localization and binding site of photosensitizer) (Delcanale et al., 2016), and other photophysical properties comprehensively reviewed elsewhere (Luksiene \& Brovko, 2013).

Another factor determining the photosensitization efficiency is the presence of components with the ability to quench produced reactive species and, in turn, protect the target organism. This could occur through endogenous light absorption within pigmented microbial cells such as $P$. aeruginosa and Porphyromonas spp., or fungi such as Aspergillus niger (D'Souza et al., 2015). Consequently, the required wavelength for photosensitizer should be beyond that of the 
endogenous pigment to achieve the desired effect through photoexcitation of photosensitizer (Wainwright \& Crossley, 2004). Furthermore, components with the ability to react with or quench the singlet oxygen could be presented within either the treated food product or the photosensitizer solution (when an extract or a mixture of bioactive components is used) such as phenols and carotenoids (Choe \& Min, 2009). Also, there should not be any overlapping of absorption bands of photosensitizer and other probable chromophores present in the food material being treated (DeRosa \& Crutchley, 2002).

There can be situations where the photosensitizers used to generate singlet oxygen will themselves react to quench it. In fact, singlet oxygen can rapidly react with a diene or olefin, which is due to its strong electrophilicity. This can be detrimental to conjugation present in a highly conjugated organic photosensitizer (e.g., phthalocyanines, porphyrins, dyes, etc.), and consequently, destroying its light absorption ability and, in turn, the formation of singlet oxygen (DeRosa $\&$ Crutchley, 2002). Photobleaching and photodegradation could then result, where the former refers specifically to the dye degradation by singlet oxygen, and the latter refers to the deterioration of singlet oxygen via the reaction with a matrix compound. Generally, $10^{3}$ to $10^{5}$ of ${ }^{1} \mathrm{O}_{2}$ can be produced by each photosensitizer, before being degraded by photobleaching or other processes (DeRosa \& Crutchley, 2002).

Overall, selection of photosensitizer mainly relies on its photophysical features and the anticipated application. There are obviously differences between the photosensitizers being used in clinical applications and those in the food industry. The preferable absorbance of clinical photosensitizers is in the red region of spectrum, which is not the first priority in the food industry because of its heating properties. Further, compared to UV with its proven bactericidal properties (Maclean, Macgregor, Anderson, \& Woolsey, 2008), visible light seems to be preferred in the food industry owing to its higher safety and enhanced transmissibility. Chemical structure of a photosensitizer influences its distribution, which is a critical factor in a successful photodynamic process. Being amphiphilic is a beneficial feature for photosensitizer, giving rise to not only water solubility but also easier crossing of cell membranes owing to the hydrophobic matrix (DeRosa \& Crutchley, 2002). Beside the mentioned criteria, a desirable photosensitizer in food safety applications should present lack of mutagenic effects, absence of toxicity and toxic by-products, be of low cost, and natural with no adverse impact on organoleptic (i.e., flavor, taste, and appearance) and nutritional properties of the treated food. A review of literature has shown the promising phototoxicity properties of the naturally occurring compound, curcumin, which can be recommended as a potential candidate for applications in food products.

\section{4 | CURCUMIN}

Curcumin $\left(\mathrm{C}_{21} \mathrm{H}_{20} \mathrm{O}_{6}\right.$; 1,7-bis-4-hydroxy-3-methoxyphenyl1,6-heptadiene-3,5-dione) is a polyphenolic compound derived from Curcuma longa $\mathrm{L}$. rhizomes (Zingiberaceae). It has a long traditional application in Chinese and Indian medicine (e.g., chicken pox, insect bites, and skin diseases) due to its well-known biological and health-promoting properties (Kolev, Velcheva, Stamboliyska, \& Spiteller, 2005). Curcumin has been approved safe as a food additive (i.e., E100; $200 \mathrm{mg} / \mathrm{kg}$ body weight is recommended as the safe limit of curcumin consumption by the FAO [ $\mathrm{Liu}, \mathrm{Li}$, et al., 2016]), which allows consumption of the compound together with food and proves its excellent biocompatibility (Wikene, Hegge, Bruzell, \& Tønnesen, 2015). In fact, natural coloring and flavoring properties of curcumin have recently drawn the food industry attention in its application in a variety of ready to eat food and beverage products. Besides, the phototoxicity of curcumin has extensively been studied (Kolev et al., 2005), and its advantages to be used as a natural photosensitizer for decontamination purposes include established efficacy against a wide spectrum of microorganisms, low cost, and availability. The effective concentrations reported for curcumin phototoxicity are far below the above-mentioned limit. Therefore, it is acceptable to be recommended as a viable and safe alternative to currently used antimicrobials in the food industry.

\section{1 | Chemical structure and biological activity}

The isolation of curcumin was first reported by Vogel in 1842 and its structure was first characterized by Lampe and Milobedeska in 1910 (Milobedzka, Kostanecki, \& Lampe, 1910). It was then synthesized and structurally confirmed by Lampe and Milobedzka in 1913 (Lampe \& Milobedzka, 1913). The four main structures of curcuminoids are shown in Figure 2, which constitute $3 \%$ to $5 \%$ of a typical C. long $\mathrm{L}$. extract with curcumin being the principal curcuminoid (Payton, Sandusky, $\&$ Alworth, 2007). The most and the least stable structures of curcuminoids are bisdemethoxycurcumin and curcumin, respectively (Tønnesen, Karlsen, \& van Henegouwen, 1986). The commercial curcumin is comprised of $77 \%$ curcumin, $17 \%$ demethoxycurcumin, and 3\% bisdemethoxycurcumin, in which the two latter are responsible for the yellow color of turmeric (Akram et al., 2010; Heger, van Golen, Broekgaarden, \& Michel, 2014).

From a structural viewpoint, curcumin or diferulylmethane contains two aromatic rings known as feruloyl with orthomethoxy phenolic OH groups (Figure 3 ). The highly polar aromatic rings are symmetrically connected via a seven-carbon 
<smiles>[2H]C(=O)OC=CC(=O)CC(=O)C=Cc1ccc(O)cc1</smiles><smiles>COc1cc(/C=C/C2=CC(=O)CC(c3ccc(O)c(OC)c3)O2)ccc1O</smiles><smiles>O=C(/C=C/c1ccc(O)cc1)CC(=O)/C=C/c1ccc(O)cc1</smiles>

F I G U R E 2 Chemical structures of curcuminoids

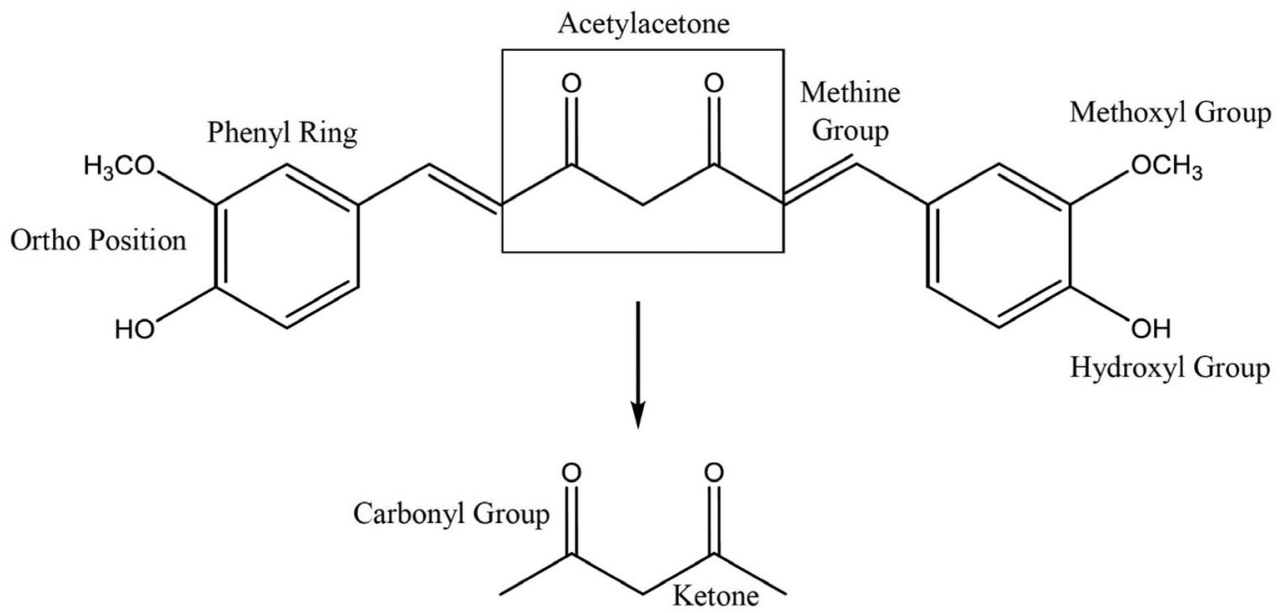

F I G U R E 3 Functional groups in the molecular structure of curcumin

aliphatic chain (i.e., bridge composed of methane-rich segments responsible for the hydrophobic nature of curcumin [Balasubramanian, 2006]), and two $\alpha, \beta$-unsaturated carbonyl groups (i.e., $\beta$-diketone moiety). The occurrence of the two main keto and enol tautomeric conformations (having different cis and trans forms; Figure 4) is owing to the intramolecular hydrogen atom transfer through the $\beta$-diketone molecule. The latter is more energetically stable in solution and solid state by strong intramolecular hydrogen-bonding than the keto form (Akram et al., 2010; Payton et al., 2007), and therefore, curcumin is usually found in its enol-tautomer form (Payton et al., 2007). The keto tautomer dominates in acidic/neutral aqueous solutions and in cell membranes, while the enolic form is predominantly found in alkaline medium (Sharma, Gescher, \& Steward, 2005).

There are different factors determining the relative contribution of keto and enol tautomeric forms in solution, including polarity of the solvent, temperature, and substitution of the aromatic rings (Priyadarsini, 2009). Advanced nuclear magnetic resonance (NMR) spectroscopy studies have confirmed the dominance of the enol form of curcumin in most of the organic solvents. However, under specific conditions (e.g.,<smiles>COc1ccc(/C=C/C(=O)CC(=O)/C=C/c2ccc3c(c2)O[IH]O3)cc1OC</smiles><smiles>COc1ccc(/C=C/c2cc(/C=C/c3ccc4c(c3)OCO4)co2)cc1OC</smiles>

F I G U R E 4 Keto-enol tautomeric equilibrium of curcumin

acidic environment), keto-enol equilibrium might be obtained (Payton et al., 2007). An increase in the solvent polarity also results in a shift in the keto-enol equilibrium toward the enol form, and therefore, loss of spectral structure (Priyadarsini, 
2009). Intramolecular hydrogen transfer leads to enolic form of curcumin in nonpolar and aprotic solvents such as deuterated chloroform (Radeglia \& Arrieta, 1998). Breaking of an intramolecular hydrogen bond with an intermolecular hydrogen bond in protic solvents, such as methanol, leads to the conversion of enol into the keto form (Priyadarsini, 2009). In fact, poor solubility of curcumin in aqueous media could be attributed to the presence of inter- and intrahydrogen bondings (Heger et al., 2014). Curcumin possesses three protons ionisable in water, one enolic and two phenolic protons (Hatcher, Planalp, Cho, Torti, \& Torti, 2008). However, based on the solvent and method of estimation, different acidity constants $\left(\mathrm{pK}_{\mathrm{a}}\right)$ have been reported for curcumin, for example, $\mathrm{pK}_{\mathrm{a}}$ of 7.7 to 8.5 for enolic, and $\mathrm{pK}_{\mathrm{a}}$ of 10 to 10.5 for the two phenolic protons (Bernabé-Pineda, Ramı́rez-Silva, Romero-Romo, González-Vergara, \& Rojas-Hernández, 2004; Priyadarsini, 2009).

Generally, the presence of different functional groups in the curcumin molecule leads to its various biological activities (Figure 3), which are $\beta$-diketo groups, carbon-carbon double bonds, and phenyl rings with various hydroxyl and methoxy substituents (Stannic). A comparable antioxidant capacity of curcumin to vitamins $\mathrm{C}$ and $\mathrm{E}$ has been demonstrated. The antioxidant capacity is caused by the potent radical scavenging ability of curcumin against different reactive species such as singlet oxygen, superoxide anion, nitrogen dioxide radicals, and therefore preventing damage to bio macromolecules (Chignell et al., 1994; Stannic \& Grouse, 2012). This antiradical activity could be attributed to an electron or abstract hydrogen-atom transfer from either the $\mathrm{CH}_{2}$ group or the phenolic $\mathrm{OH}$ group of the $\beta$-diketone moiety to a reactive free radical (Kolev et al., 2005; Stannic \& Grouse, 2012). The number of hydroxyl groups and their locations in the aromatic ring determines the oxidation mechanism and antioxidizing activity of curcumin, with the enol form more susceptible to oxidation than the keto form (Masek, Chrzescijanska, \& Zaborski, 2013).

The light absorption ability of curcumin is also related to its chemical structure that is the presence of alternating single and double bonds in the backbone carbon chain, being considered as a molecular conjugative system. The broad absorption spectrum of curcumin $(\sim 430 \mathrm{~nm})$ is due to $\pi \rightarrow \pi^{*}$ transitions of the enone group of curcumin in its enolic form in the solution (Shen \& Ji, 2007). The perfect planar configuration of enol form allows resonance within the two benzene rings. This, in turn, gives rise to a linear extended $\pi$-electron system leading to an intense absorption peak in the visible region of light spectrum (ca. $420 \mathrm{~nm}$ ). However, the twisted structure of keto tautomer results in shifting the absorption maximum to the near-UV region (ca. $389 \mathrm{~nm}$ ), which is due to the lack of the large conjugative system present in enol form (Shen \& Ji, 2007).

\section{2 | Curcumin photoactivity}

Recently, research has focused on the enhanced antimicrobial activity of curcumin through photoexcitation once being exposed to light (with maximum absorption of 408 to $434 \mathrm{~nm}$; Mandeville, Froehlich, \& Tajmir-Riahi, 2009) and production of cytotoxic reactive oxygen species (Haukvik et al., 2009; Hu et al., 2018; Preis et al., 2019; Randazzo, Aznar, \& Sánchez, 2016). Interestingly, both oxygen-dependent and oxygen-independent mechanisms are known to be responsible for phototoxicity of curcumin mediated by excited state of curcumin and reactive oxygen radicals (e.g., singlet oxygen $\left[{ }^{1} \mathrm{O}_{2}\right]$ and superoxide radicals $\left[\mathrm{O}_{2}^{-}\right]$) (Qian et al., 2016). Several studies have confirmed the dual activity of curcumin being either free radical (e.g., ${ }^{1} \mathrm{O}_{2}$ ) scavenger or producer (Priyadarsini, 2009). Nevertheless, some authors have suggested the hypothesis of differential and selective behavior of curcumin as an antioxidant in normal cells and prooxidant in tumor cells (Aggarwal \& Sung, 2009). Moreover, alterations to curcumin structure can lead to the loss of the radical scavenging ability, such as replacing the hydroxyl group of curcumin with another functional group (Vajragupta et al., 2003).

Different factors influence the phototoxicity of curcumin, including hydrogen bonding and charge delocalization (Barik \& Priyadarsini, 2013), as well as photostability (Sundaryono et al., 2003). In fact, photodegradation of curcumin is highly likely to occur in both solution and solid forms leading to accumulation of photoproducts, with absorbance at the same wavelength range (Ansari, Ahmad, Kohli, Ali, \& Khar, 2005; Chignell et al., 1994). Furthermore, phototoxicity of curcumin is highly dependent on solvent through polarity, hydrogen bond donating and accepting properties, and $\pi$ bonding nature (Priyadarsini, 2009). This was confirmed by steady-state fluorescence spectroscopic studies on curcumin, with high susceptibility of fluorescence spectrum, fluorescence maximum, and the fluorescence quantum yield to the solvent. Accordingly, based on the solvent used, considerable variation in Stokes' shift from 2,000 to $6,000 \mathrm{~cm}^{-1}$ ( $\sim 30$ to $140 \mathrm{~nm}$ ) was observed (Khopde, Indira Priyadarsini, Palit*, \& Mukherjee, 2000; Nardo et al., 2008). It should be mentioned that compared to absorption, the fluorescence intensity is more sensitive to the solvent nature (Nardo et al., 2008). An increase in solvent polarity leads to not only shifting the keto-enol equilibrium toward the enol tautomer, but also forming intermolecular hydrogen bond, and consequently, causes an increase in Stokes shift (i.e., the difference between maximum absorption and maximum fluorescence wavelengths) and loss of spectral structure (Chignell et al., 1994; Nardo et al., 2008). Intermolecular hydrogen bonding in protic solvents results in an enhanced stabilization having both cis and trans enol conformers, which the latter could be the reason for the shoulder 
appearing on curcumin absorption spectra in these solvents (Emsley, 1984).

Dissolving curcumin in protic solvents (i.e., H-bonding solvents), such as methanol and ethanol, gives rise to negligibly small fluorescence quantum yield and lifetime, while higher yields and lifetime were observed in aprotic solvents such as benzene, acetonitrile, chloroform, and deuterated chloroform (Khopde et al., 2000; Nardo et al., 2008). However, the lowest fluorescence quantum yield and the shortest lifetime were observed in cyclohexane, a nonpolar- and nonhydrogenbonded solvent (Nardo et al., 2008). Negligible fluorescence of curcumin was also observed in aqueous organic solutions, in which water quenches the fluorescence intensity through curcumin $^{-} \mathrm{H}_{2} \mathrm{O}^{+}$complex formation, which is stable and nonfluorescent (Bong, 2000).

The phototoxicity of curcumin is generally through nonradiative processes (mainly through intra- and intermolecular excited state proton transfer) rather than intersystem crossing and radiative transformations, which is confirmed by its very low fluorescence quantum yield $(\leq 0.2)$ (Priyadarsini, 2009). The short fluorescence lifetime of curcumin is also affected by salvation, cis-trans isomerization, excited state intramolecular proton transfer, and competing nonradiative processes, which is affected by solvent (Nardo et al., 2008). Excitedstate intramolecular proton transfer is shown to be the leading mechanism in excited curcumin decay. However, the occurrence of other decay mechanisms is also indicated by both the three-band fluorescence spectrum and the three-exponential fluorescence decay (Nardo et al., 2008). Different studies have shown that curcumin exhibits two solvent-dependent excited states, namely, excited-state proton transfer (ESPT) in nonpolar solvents and salvation in polar protic solvents (Ghatak, Rao, Mandal, Ghosh, \& Sarkar, 2012). Generally, intermolecular ESPT and electronic salvation occur in the presence of polar protic solvents, due to the intermolecular hydrogen bond between curcumin and solvent molecules (Ghosh, Mondal, \& Palit, 2010).

\section{3 | Curcumin solubility}

The main prerequisite for photoinactivation of microorganisms is accumulation of photosensitizer within or in the vicinity of the target microbial cell wall, followed by being translocated into the cytoplasm containing different critical targets (Lukšiene, 2005). However, the efficient utilization of curcumin having a hydrophobic nature is limited, mostly due to its low water solubility and poor chemical stability (in particular in alkaline solutions) (Heger et al., 2014). In general, the poor water solubility of photosensitizers such as curcumin drives their tendency to aggregate in solution, which counteracts the phototoxic potential through no attachment and penetration into bacterial cell. As a result, low singlet oxygen quantum yields of photosensitizer aggregates occur (Konan, Gurny, \& Allémann, 2002). Differences in curcumin concentration as well as the solvent used for dissolving curcumin could be effective in the degree of membrane damage to microorganisms caused by curcumin-based photosensitization (Bhavya \& Hebbar, 2019a; Jiang, Leung, Hua, Rao, $\& \mathrm{Xu}, 2014)$. However, a study showed no enhancement in photo-killing ability by increasing the concentration of photosensitizer in solution, which could be attributed to the occurrence of saturation or further aggregation of photosensitizer (Glueck, Schamberger, Eckl, \& Plaetzer, 2017) rooting from its poor solubility.

Referring to curcumin solubility, different factors influence its dissolution rate such as the nature of the curcumin crystals (e.g., structure, morphology, crystallinity, surface area), solvent (e.g., polarity), and physical conditions applied (e.g., temperature, stirring speed, and sonication) (McClements, 2012). Taking mixing time as an example, higher curcumin solubility in soybean oil was obtained by $48 \mathrm{hr}$ mixing $(\sim 7,380 \mu \mathrm{g} / \mathrm{mL})$ (Setthacheewakul, Mahattanadul, Phadoongsombut, Pichayakorn, \& Wiwattanapatapee, 2010) compared to 10 min mixing ( $0.1834 \mu \mathrm{g} / \mathrm{mL}$ ) (Lin, Lin, Chen, Yu, \& Lee, 2009). Different approaches have been investigated to increase the solubility of curcumin, such as dissolving it in deep eutectic solvents $(>0.05 \mathrm{mg} / \mathrm{mL})$, which exist naturally in all living cells. Compared to cyclodextrin, ethanol, and buffer ( $\mathrm{pH} 8.0)$, higher hydrolytic stability and photostability were obtained in deep eutectic solvents. This, in turn, resulted in an enhancement of photoinactivating $E$. coli in lower concentrations $(1.25 \mu \mathrm{M})$ than other previously studied formulations of curcumin (Wikene, Bruzell, \& Tønnesen, 2015).

Curcumin is readily soluble in polar solvents, such as 2-butanone $(\sim 2.17 \mathrm{mg} / \mathrm{mL})$, isopropanol $(\sim 3.93 \mathrm{mg} / \mathrm{mL})$, ethanol $(\sim 5.6 \mathrm{mg} / \mathrm{mL})$, acetone $(\sim 7.75 \mathrm{mg} / \mathrm{mL})$ (Heger et al., 2014), and dimethyl sulfoxide ( $\sim 20 \mathrm{mg} / \mathrm{mL}$ ) (Khopde et al., 2000). Also, solubility of curcumin in other solvents such as dimethylformamide, methanol, chloroform, and acetonitrile has been reported, with moderate solubility in hexane, carbon tetrachloride tetrahydrofuran, cyclohexane, tert-butanol, and dioxane (Mandeville et al., 2009). High lipophilicity of curcumin has been confirmed by its $\log p$ value of 3.29 , which determines its partitioning in octanol to a greater extent than aqueous medium (PubChem-969516). Accordingly, curcumin is sparingly soluble in water at acidic or neutral $\mathrm{pH}(11 \mathrm{ng} / \mathrm{mL}$, $25^{\circ} \mathrm{C}$ ) (Tønnesen, Másson, \& Loftsson, 2002), and sparsely soluble at alkaline $\mathrm{pH}$ due to phenolate ion formation through donating of $\mathrm{H}^{+}$ion by its acidic phenolic group (Jagannathan, Abraham, \& Poddar, 2012). Being subjected to alkaline condition, however, curcumin (diferuloyl-methane) experiences rapid hydrolytic degradation into acetone, ferulic acid, feruloylmethane, and vanillin, which, in turn, gives rise to a reduction in its desirable yellow color (Heger et al., 2014; Mondal, Ghosh, \& Moulik, 2016). It is noteworthy to mention that 
the maximum absorption of curcumin in glacial acetic acid is at $422 \mathrm{~nm}$, while this wavelength changes to ca. $463 \mathrm{~nm}$ in basic aqueous medium, in which the bright yellow color turns bright red due to the formation of the bright red phenoxide ion through ionization of phenolic OH-groups (Bernabé-Pineda et al., 2004). More stability of curcumin under acidic condition is due to the keto tautomer predominance rooted from the presence of a highly activated carbon atom in the heptadienone linkage. Further, the delocalization of the unpaired electron on the adjacent oxygens results in having very week $\mathrm{C}-\mathrm{H}$ bonds on the respected carbon. However, enolate form of heptadienone linkage predominates in the alkaline environments leading to its instability (Jovanovic, Steenken, Boone, $\&$ Simic, 1999). Moreover, curcumin degradation in aqueous media at neutral $\mathrm{pH}$ was accelerated in the presence of salt $(\mathrm{NaCl})$, which could be attributed to the catalytic activity of $\mathrm{Cl}^{-}$ions in addition to $\mathrm{OH}^{-}$ions (Mondal et al., 2016).

Natural oils derived from plant material have also been proposed as solvents for curcumin. Compared to longchain triglycerides, short-chain triglycerides with more polar groups (i.e., oxygen) per mass unit exhibit more dipoledipole interactions with curcumin, and therefore, favoring curcumin solubilization (Araiza-Calahorra, Akhtar, \& Sarkar, 2018). Various studies have shown the temperature dependency of curcumin solubility in medium chain triglyceride by using high temperature of up to $100{ }^{\circ} \mathrm{C}$ (Araiza-Calahorra et al., 2018), which was even higher than that of ultrasonic $(390 \mathrm{~W}, 1 \mathrm{~s}$ interval for $30 \mathrm{~min}$ ) and microwave treatment (780 W, 30 s) (Ma et al., 2017). It should be noted that dissolved curcumin might precipitate and crystallize once being cooled, if its concentration exceeds the supersaturation level (McClements, 2012). However, curcumin might be degraded by prolonged heating during dissolving in the oil phase (Wang, Liu, Xu, Yin, \& Yao, 2016). Surfactants can also be used to boost curcumin solubility due to its hydrophobic nature. The methylene-rich chain and enolic and phenolic groups of curcumin can interact hydrophobically and electrostatically with hydrophobic and positively charged head groups of cationic-nonionic surfactants such as polysorbate 80 (Kumar, Kaur, Kansal, Chaudhary, \& Mehta, 2016).

Nevertheless, the advent of encapsulation technology has opened up ample opportunity to address the poor solubility of bioactive components as well as protecting them against environmental factors (e.g., pH, oxygen, enzymes, and temperature). Various encapsulation techniques have been extensively investigated to improve the solubility of curcumin in aqueous solutions and its protection from chemical degradation such as liposome (Ibrahim, Tagami, Kishi, \& Ozeki, 2018), nanoparticles (Moghaddasi, Housaindokht, Darroudi, Bozorgmehr, \& Sadeghi, 2018), and nanoemulsions (Abdou, Galhoum, \& Mohamed, 2018). One study, for example, showed an 812-fold increase in aqueous solubility of curcumin through encapsu- lating it in soy protein isolate via coacervation, followed by spray drying (Tapal \& Tiku, 2012). Curcumin solubility in water was also increased by 38.6-fold in gelatin particles using electrohydrodynamic atomization (Gómez-Estaca, Balaguer, López-Carballo, Gavara, \& Hernández-Muñoz, 2017).

\section{4 | Curcumin encapsulation}

Generally, entrapping the active component (i.e., core material) within a solid or liquid immiscible substance (i.e., carrier or wall material) is defined as encapsulation, creating particles with a size ranging from $10 \mathrm{~nm}$ to $10 \mu \mathrm{m}$ (Donsì, Sessa, \& Ferrari, 2016). Protecting bioactive components from adverse chemical changes by minimizing its reactivity (i.e., during storage, transport, and processing), masking undesirable sensorial attributes (i.e., off-flavor and odors), and having a controlled and sustainable release can be named as distinct advantages of encapsulation (Fang \& Bhandari, 2010). Nanodelivery systems can be influential in tackling the drawbacks of intrinsic properties of photosensitizers such as low solubility in aqueous media, off-target accumulation, low permeability in cell membranes, and any unwanted side effects such as discoloration (MacEwan, Callahan, \& Chilkoti, 2010).

The main goal of designing an effective delivery system is controlled release at the right time and right place, triggered by external stimuli such as $\mathrm{pH}$-change, redox environment, enzymes, temperature change, and light, which influence the shell permeability by initiating morphological changes (Tylkowski et al., 2017). Photoresponsive delivery systems can thus be applied on photosensitizers to not only protect them from photo- or hydrolytic degradation during long-term storage and aggregation in aqueous media, but also enhance their photokilling efficacy through increasing their cellular uptake (Pan et al., 2015). A few examples of successfully developed photoresponsive delivery systems for curcumin are presented in Table 2.

Generally, a photoresponsive delivery system is composed of a polymeric network and a protective moiety, usually a photochromic chromophore as the functional part, which captures the illuminated wavelength and converts to a chemical signal through isomerization, cleavage, or dimerization (Jerca, Jerca, $\&$ Stancu, 2018). However, the desired properties of a photoactive moiety are broad applicability, photochemical stability, and fast response to required wavelength illumination. Having these characteristics, azobenzenes are mostly utilized in designing photoresponsive delivery systems (Shao et al., 2017). Furthermore, various factors including beam diameter, light intensity, wavelength, and duration of exposure should be reconsidered when designing a photoresponsive delivery system. Stronger absorption abilities of the chromophores can result in using lower radiation energies and even lower radiation times (Fomina, Sankaranarayanan, \& Almutairi, 2012). 

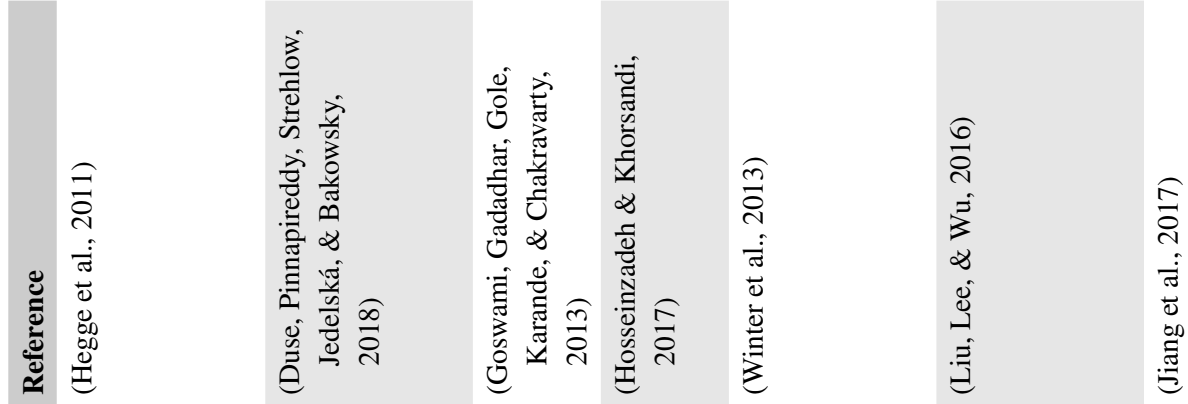

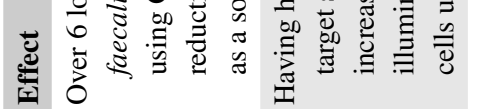
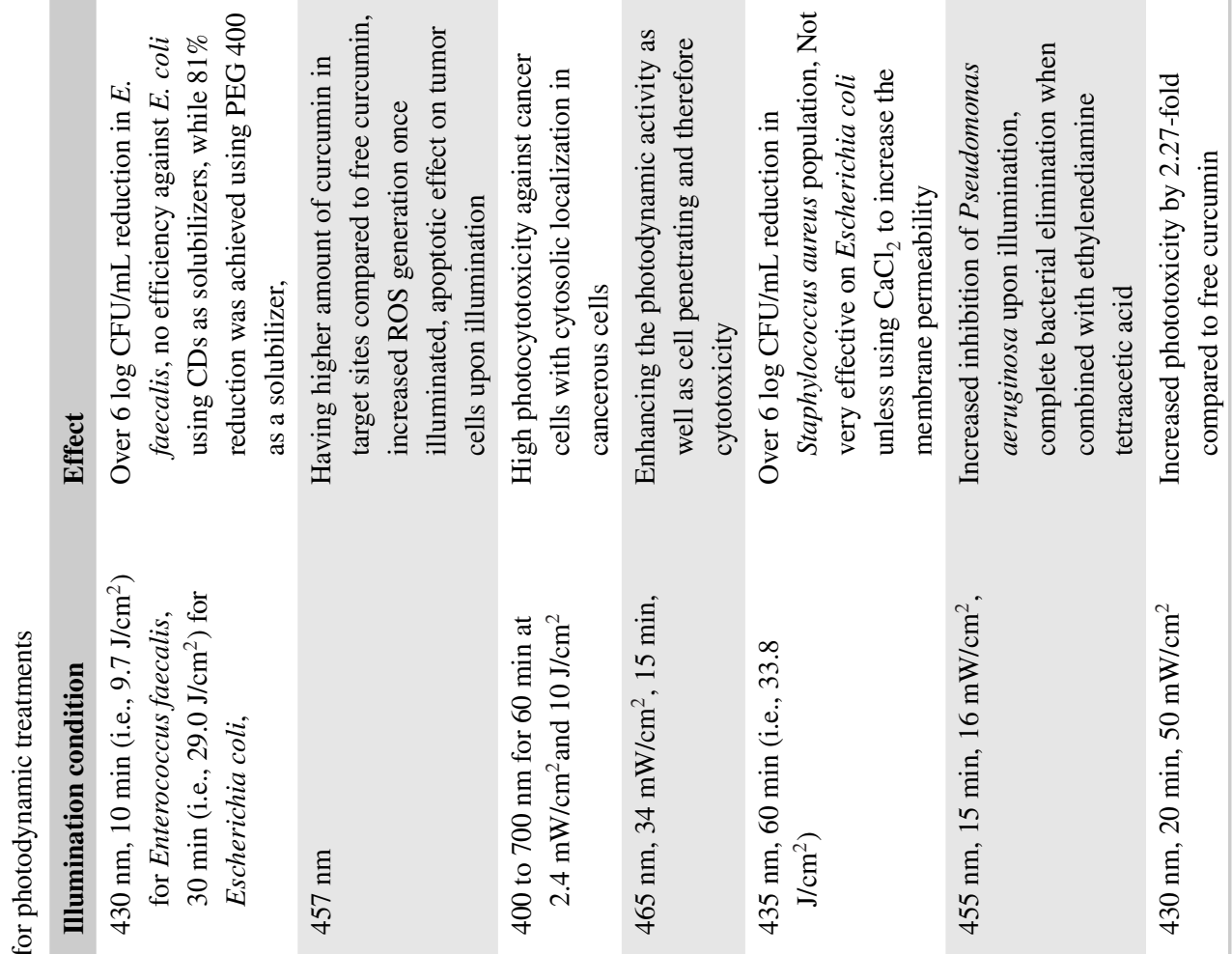

है

है

है

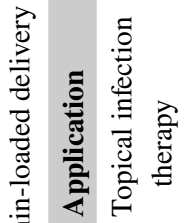

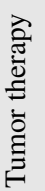
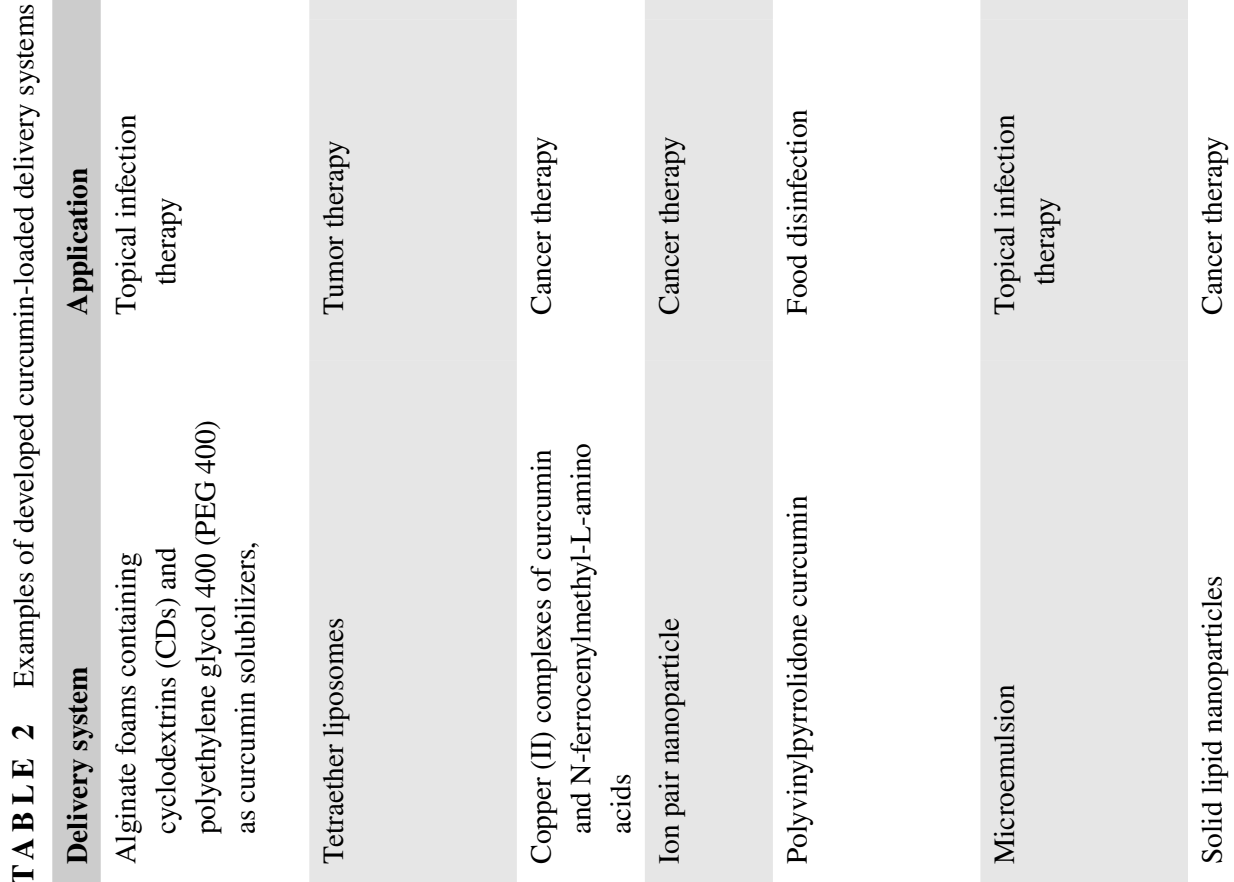
Metals can also be used as photoactive component in the structure of delivery systems such as gold nanoparticles, in which metal would be photoexcited via the generation of a strong resonance with illuminated light frequencies leading to coherent oscillation of metal conduction band electrons. This, in turn, gives rise to localized heat generation (Link \& ElSayed, 2000), which could have adverse impacts on food products. These photolabile moieties can be conjugated to alcohols, phenols, and amino acids to induce photoresponsiveness to the produced polymeric system (Shembekar, Chen, Carpenter, \& Hess, 2005). Photoactive moieties have been successfully incorporated into a variety of delivery systems, such as metal nanoparticles (Borges, Rodrigues, Reis, \& Mano, 2014), ZnO nanorods (Aponiene, Serevičius, Luksiene, \& Juršènas, 2017), and liposomes (Singh et al., 2018).

The light-triggered release is mainly based on three photochemical mechanisms, namely, photoisomerization, photocross linking, and photosensitization induced oxidation. A reversible or irreversible cyclic transformation between isomers is called photoisomerization, through either dissociation process with bond cleavage such as spiropyran, or cistrans isomerization without bond cleavage such as azobenzene (Szymanśki, Beierle, Kistemaker, Velema, \& Feringa, 2013). However, photo-crosslinking or photopolymerization can occur through illuminating a polymerizable double bond directly or in the presence of a sensitizer, hydrophobic to hydrophilic alteration of polymers, and accordingly structural destruction of the carrier (Fomina et al., 2012; Szymanśki et al., 2013). Moreover, strong oxidizing agents are responsible for oxidizing plasmogenic lipids and therefore disrupting biomembranes in photosensitization-induced oxidation, which are produced through illuminating a photosensitizer (Thompson, Gerasimov, Wheeler, Rui, \& Anderson, 1996).

More interestingly, encapsulation technology can be beneficial in enhancing the photokilling ability of photosensitizers through better accumulation and bonding as well as better release close to the target microorganisms. This is due to the short lifetime and diffusion distance of reactive oxygen species with high reactivity and instability (DeRosa \& Crutchley, 2002; Wainwright \& Crossley, 2004). The electrostatic charge of photosensitizers can be modified, leading to an increased affinity for the target microorganism. Cationic photosensitizers, for example, have been shown to be more efficient against a broad spectrum of bacteria (Lacey \& Phillips, 2001), because of a slightly negative charge of bacterial cells at neutral pH (Romanova et al., 2003). Therefore, photosensitizers can be conjugated or encapsulated with positively charged polymers. To prove this theory, the conjugation of chitosan with porphyrins, incorporation of porphyrins into polymeric films (Funes et al., 2009), or conjugation of polyvinyl amine with Phloxine B (photoactive dye) (Brovko, 2010) was tested. This resulted in an enhancement in bactericidal activity of the photosensitization process through better localization of photosensitizer in the vicinity of the target microorganism. Fungal susceptibility to photosensitization appears to be unrelated to charge, which reflects the differences in external cell structures (Wainwright \& Crossley, 2004). Studies have, however, shown the better interaction of free curcumin molecules in solution with the surface of bacterial cell, compared to those encapsulated in a carrier such as cyclodextrin or micelle (Hegge, Nielsen, Larsen, Bruzell, \& Tønnesen, 2012). This could be attributed to the prolonged release time, which can be addressed through modifying light intensity, illumination time, and even inserting chromophores within the carrier formulation to enhance the photoresponsivity. On the other hand, remarkable increase in quantum yield of singlet oxygen was reported through encapsulating hydrophobic hypericin in protein-based carriers using apo-myoglobin and $\beta$-lactoglobulin (Delcanale et al., 2015). Immobilizing photosensitizers might reduce the quantum yield; however, it can bring about several advantages in practical applications that outweigh its shortcoming. These are the possibilities to recover and reuse the photosensitizers to benefit environmentally and economically, simple isolation of their photochemical reaction products from the photosensitizer, and the flexibility to be employed in a number of solvents (DeRosa \& Crutchley, 2002).

Attempts have been made to enhance the photoactivity of curcumin through encapsulation. Photolabile but thermally stable curcumin lyophilizates were obtained in hydroxypropyl methylcellulose, methyl- $\beta$-cyclodextrin and hyaluronic acid, or hydroxypropyl methylcellulose and hyaluronic acid. Curcumin loading in produced amorphous solid dispersions was $1.4 \%$ to $5.5 \%(\mathrm{w} / \mathrm{w})$, which were rapidly dissolved in water. Over 6-log CFU/mL reduction in Enterococcus faecalis and E. coli counts was achieved using produced lyophilizates ( 0.5 to $10 \mu \mathrm{M}$ of curcumin) and blue light illumination (11 to $16 \mathrm{~J} / \mathrm{cm}^{2}$ ) (Wikene et al., 2015). Moreover, curcumincyclodextrin complex was used as a photoactive antimicrobial coating on polyethylene terephthalate, which showed to be effective against E. coli (Shlar, Droby, \& Rodov, 2018). Cassava hydrogels entrapping curcumin as photosensitizer was applied as a coating on sausages to prevent microbial crosscontamination after processing. The developed hydrogels showed photoinactivation of Listeria innocua both in vitro by $5 \log \mathrm{CFU} / \mathrm{mL}$ and on sausages by $4 \log \mathrm{CFU} / \mathrm{mL}$ under UVA illumination (5 to $15 \mathrm{~min}, 4{ }^{\circ} \mathrm{C}$ ), demonstrating a sustainable light-activated antimicrobial activity (Tosati, de Oliveira, Oliveira, Nitin, \& Monteiro, 2018). An increase in cell uptake and phototoxicity of curcumin against oral carcinoma cells and tumor spheroids was demonstrated through encapsulating in silica nanoparticles (Gupta, Das, \& Sharma, 2014). Further studies on food-compatible and industry-applicable delivery systems are, however, required to maximize the advantage of this safe and green technology in the food industry. 


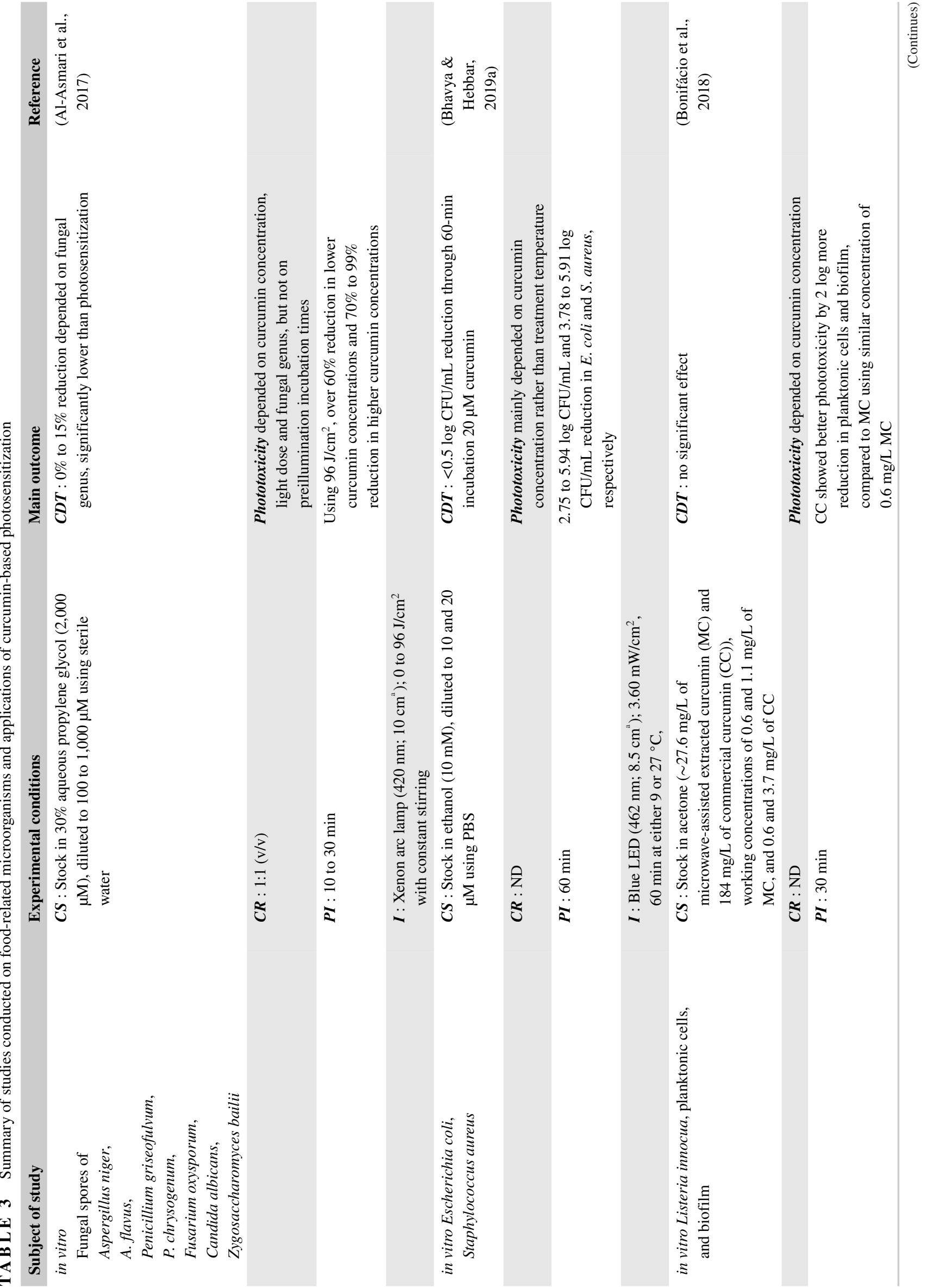




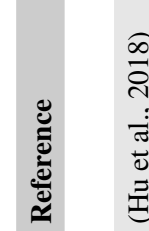

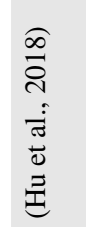

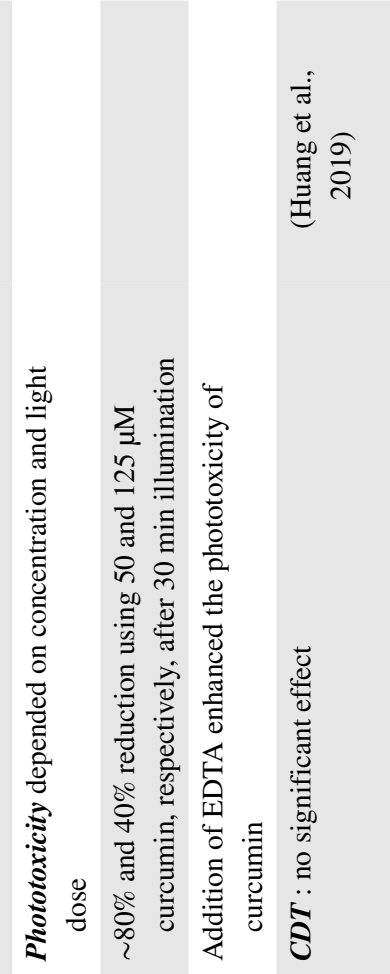

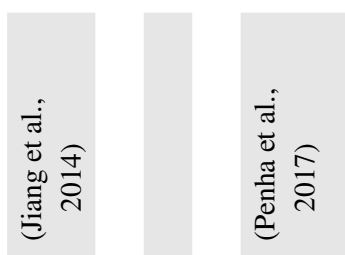

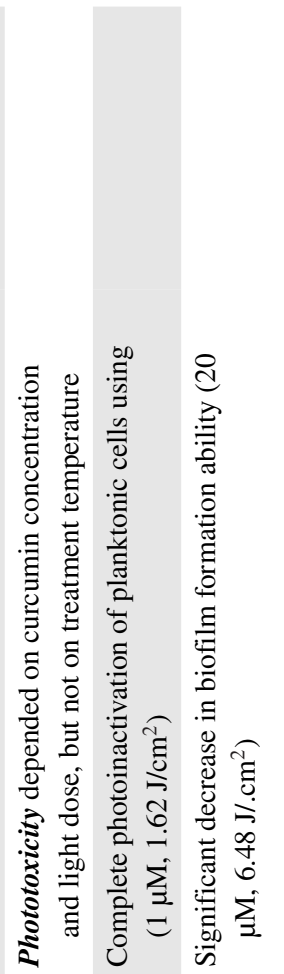

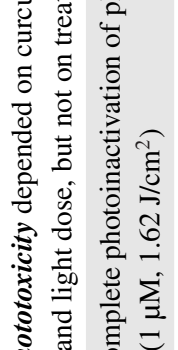
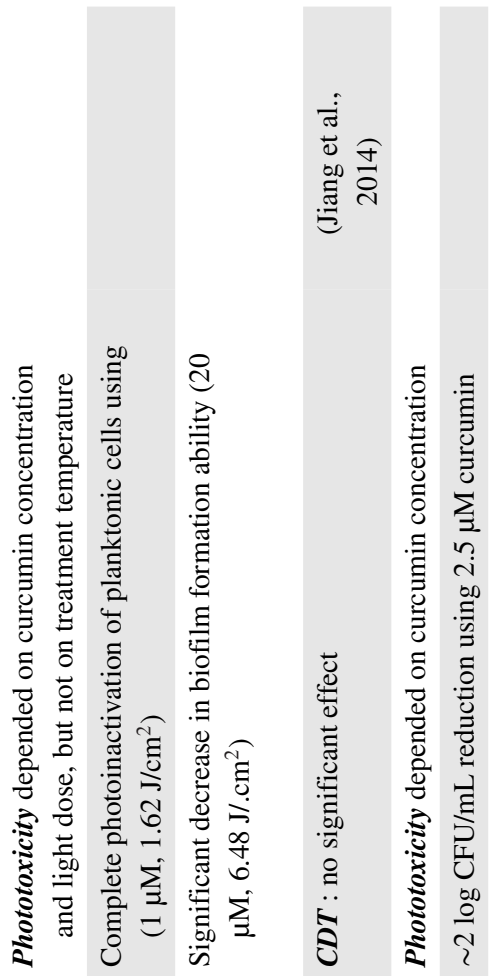
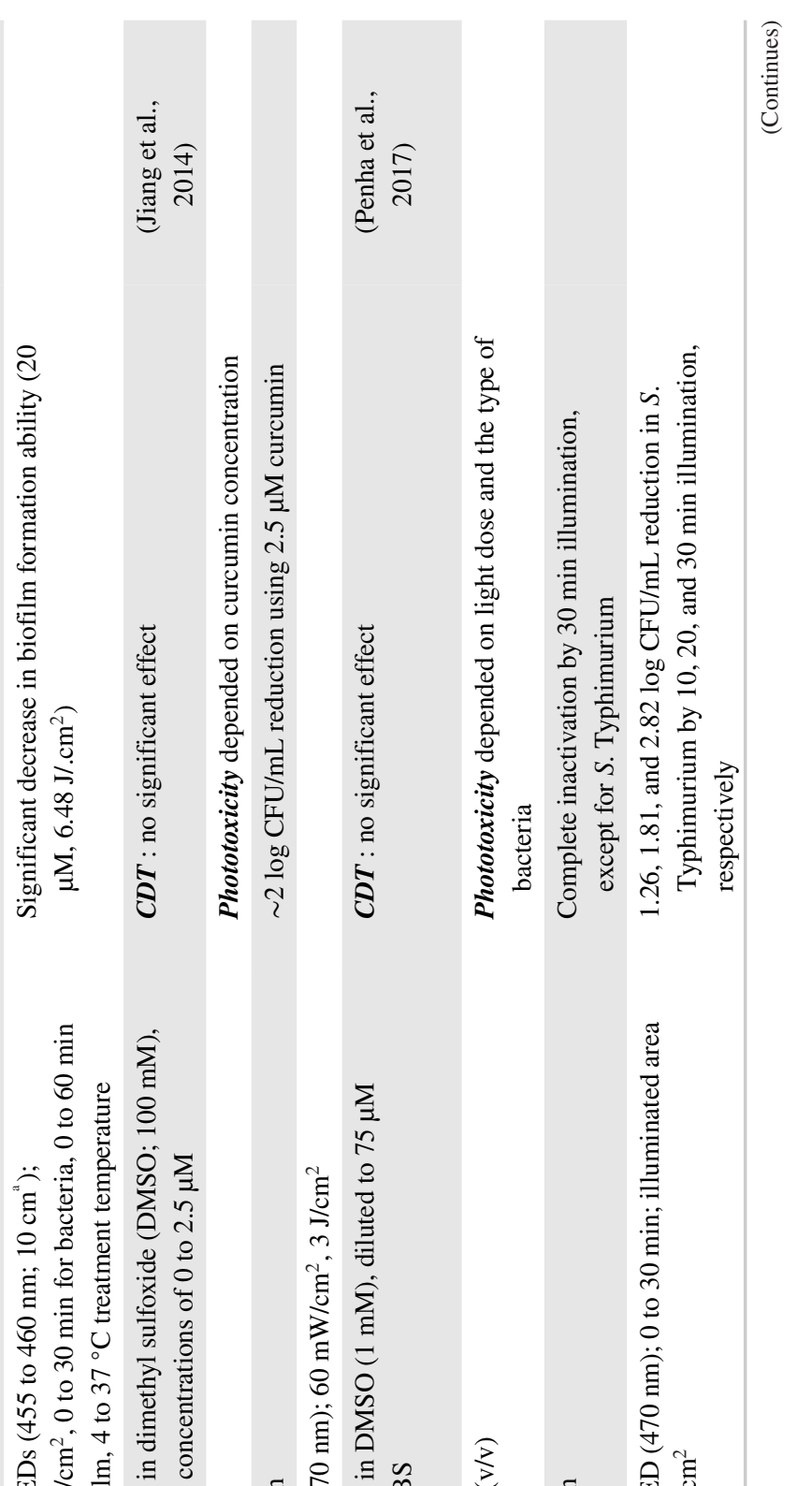

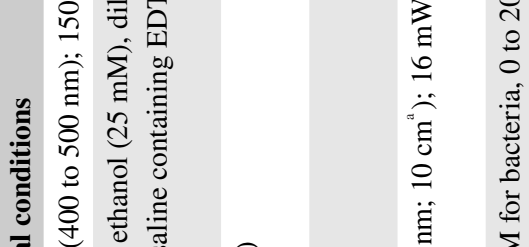

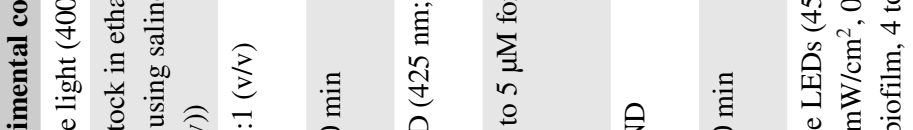

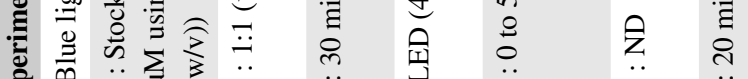

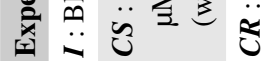

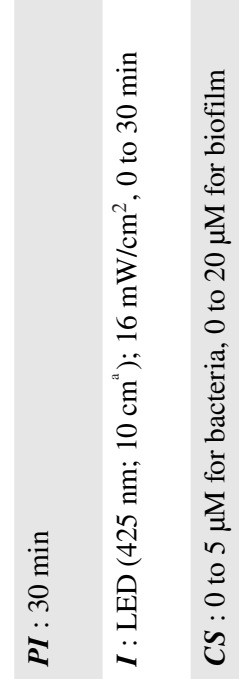

$\approx$

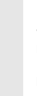

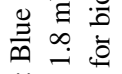
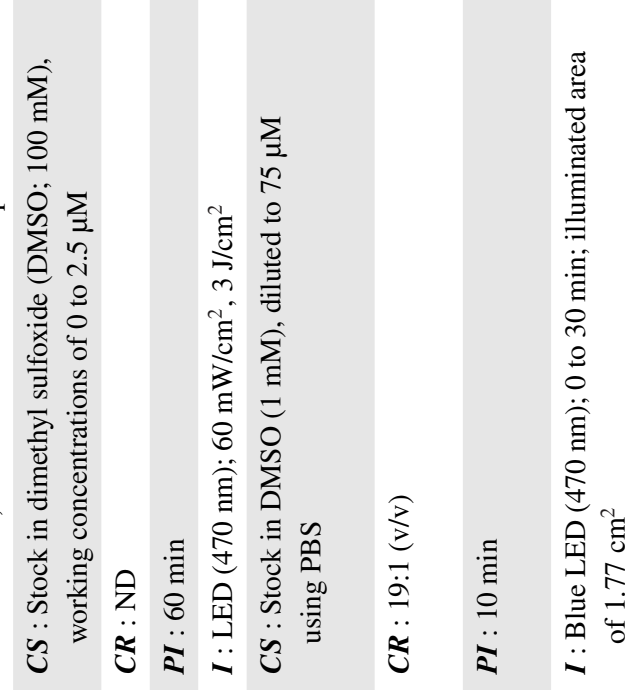

I
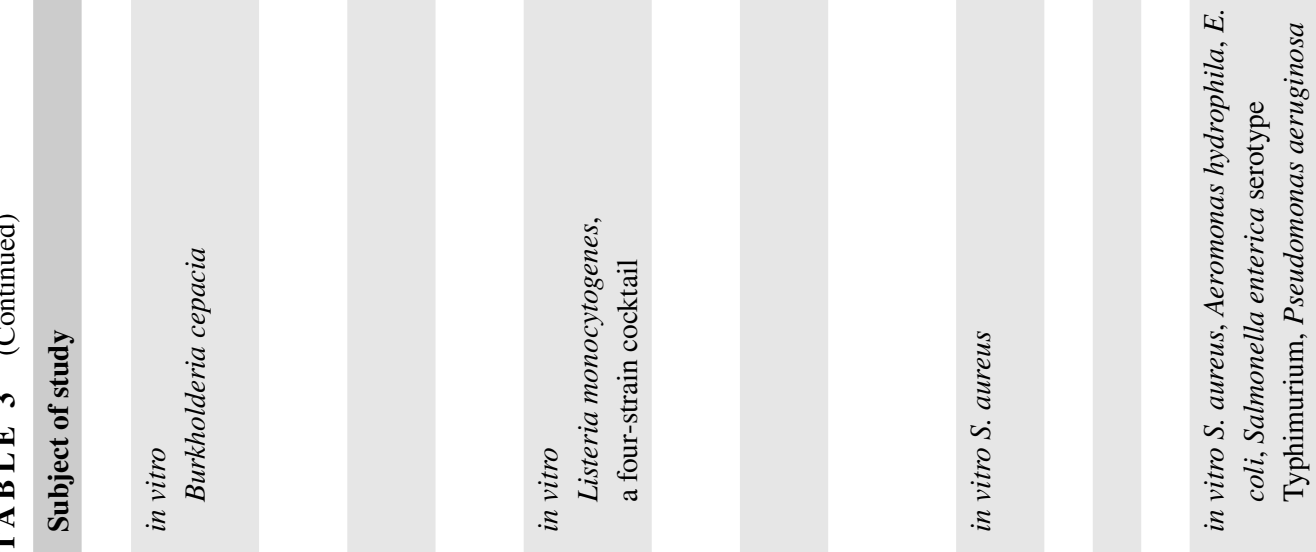

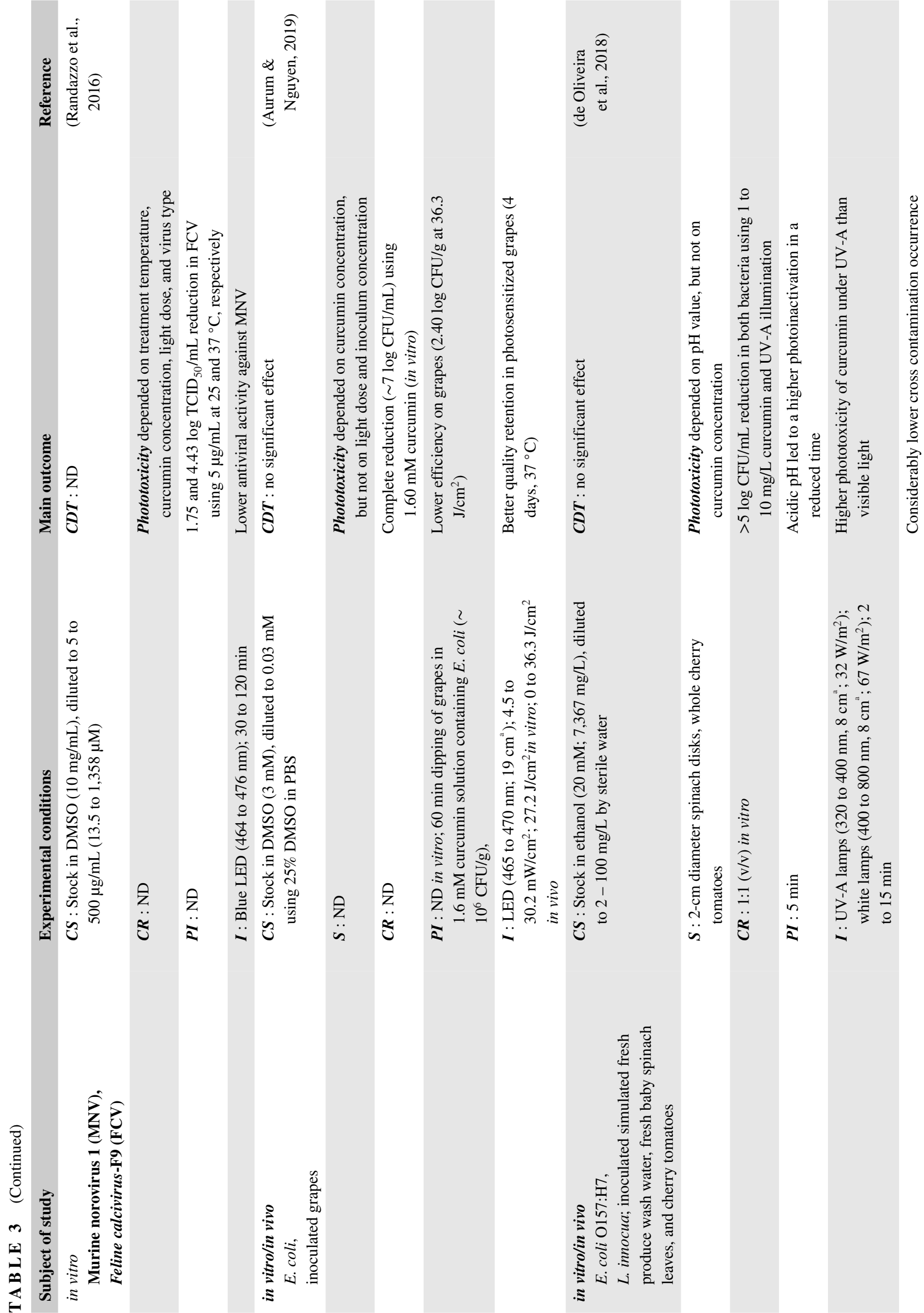

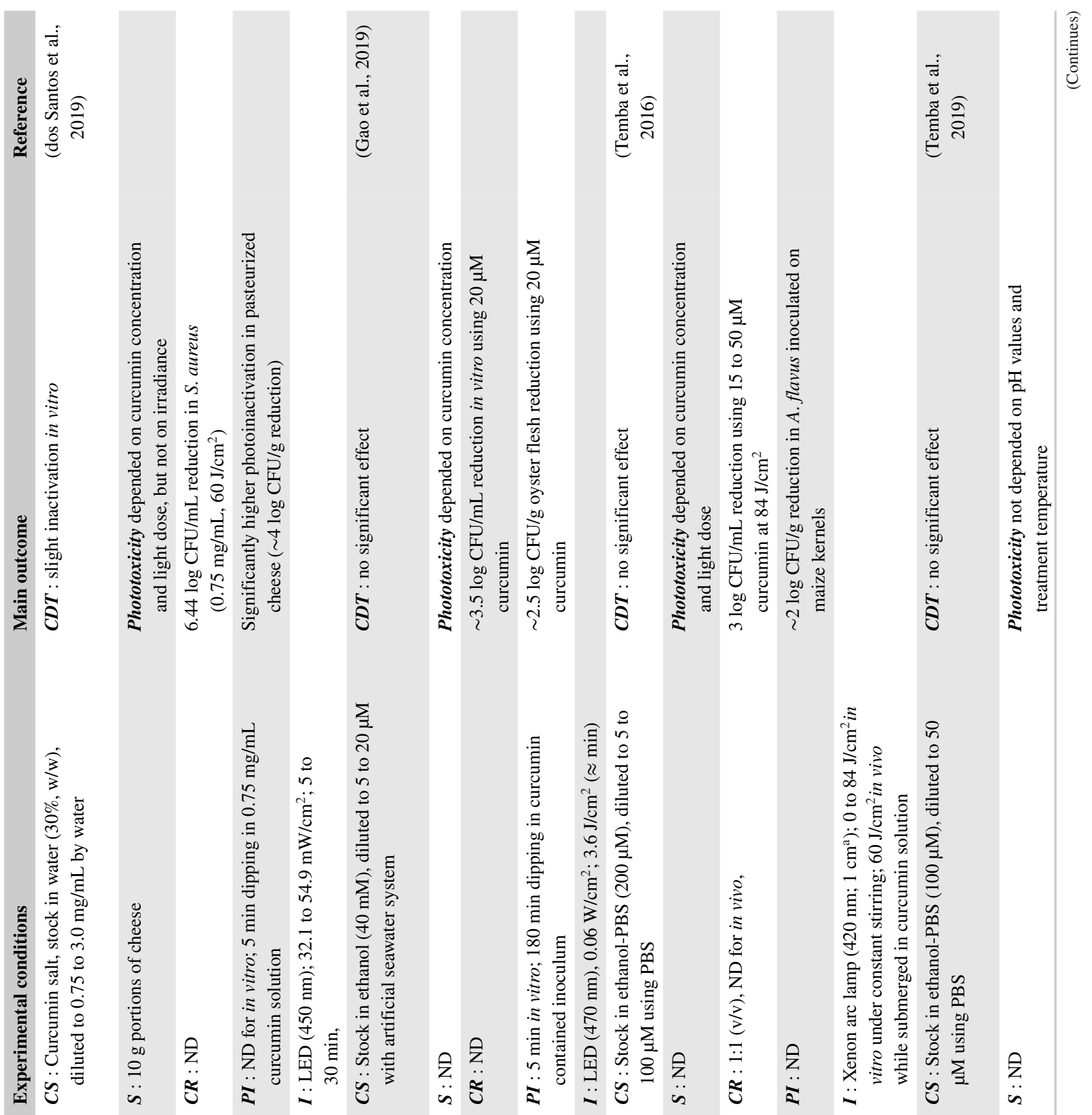

氖
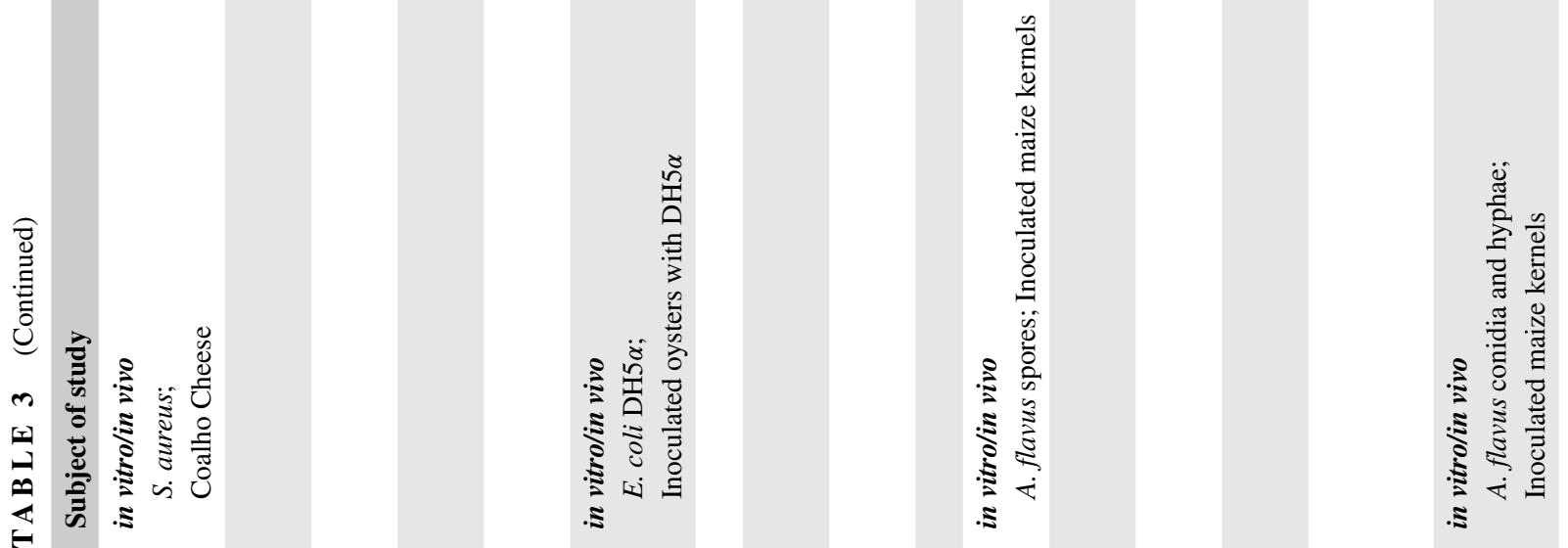

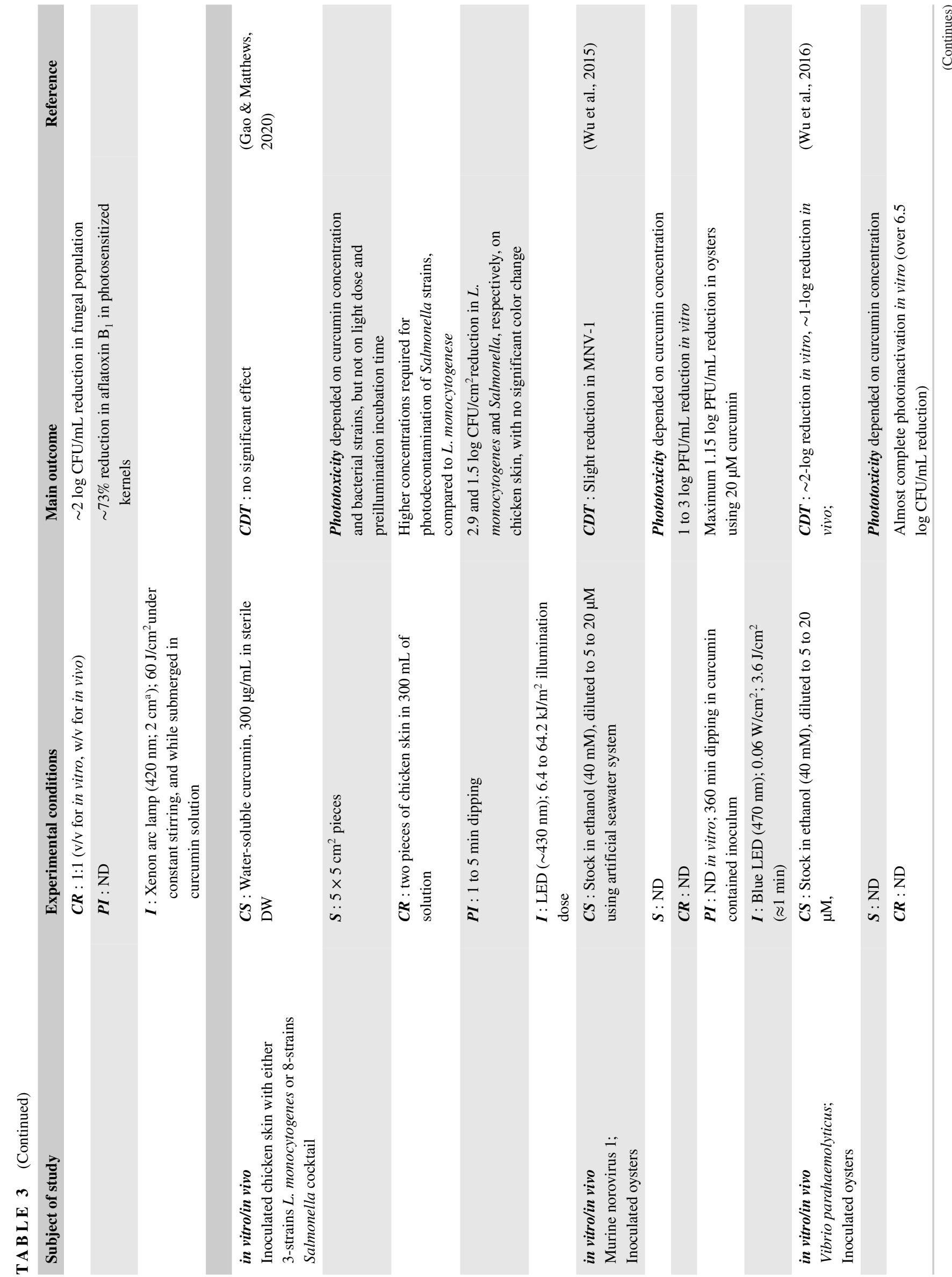

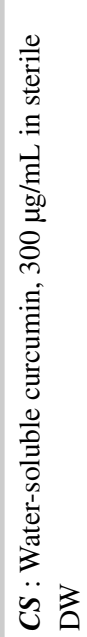
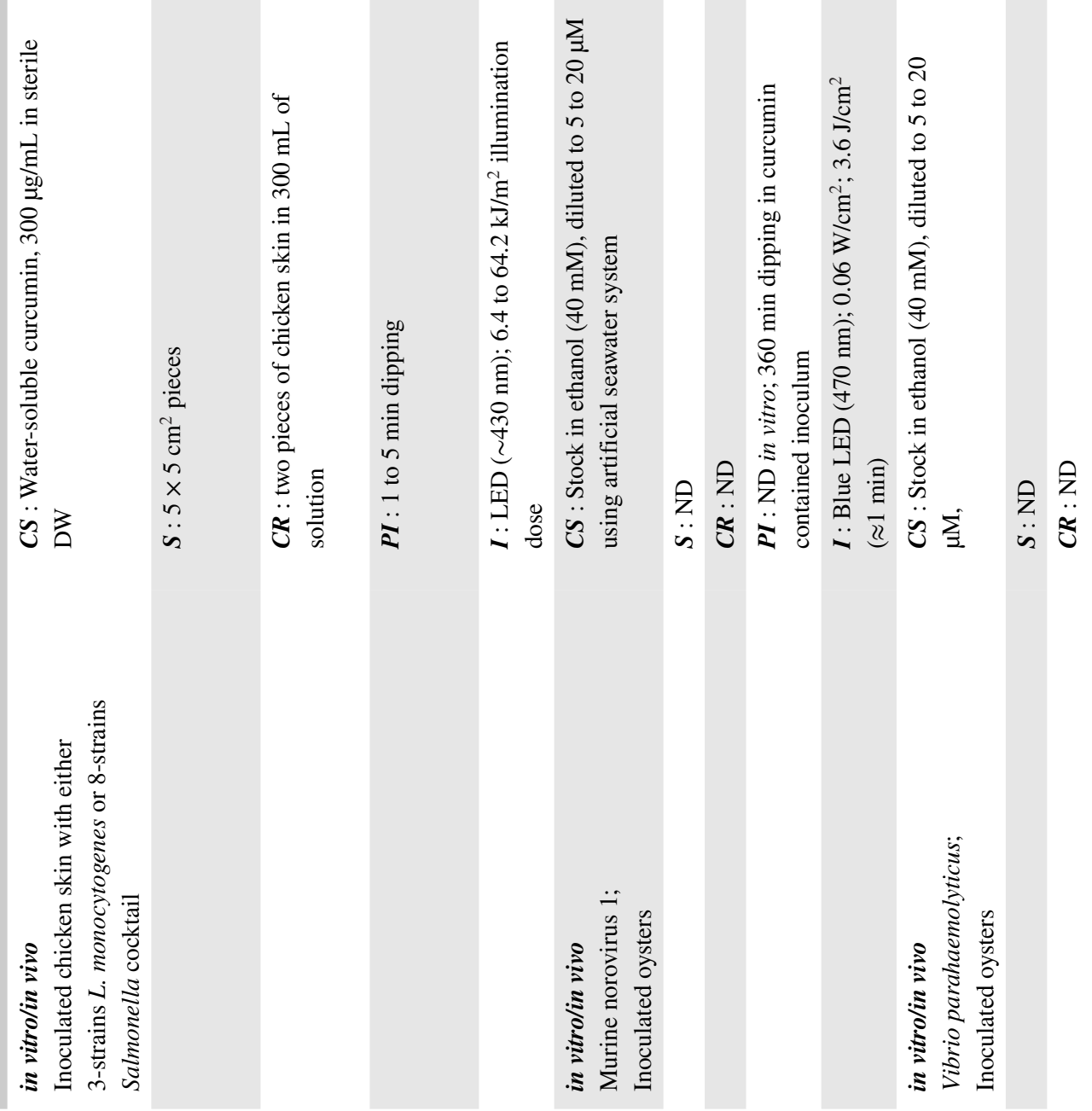

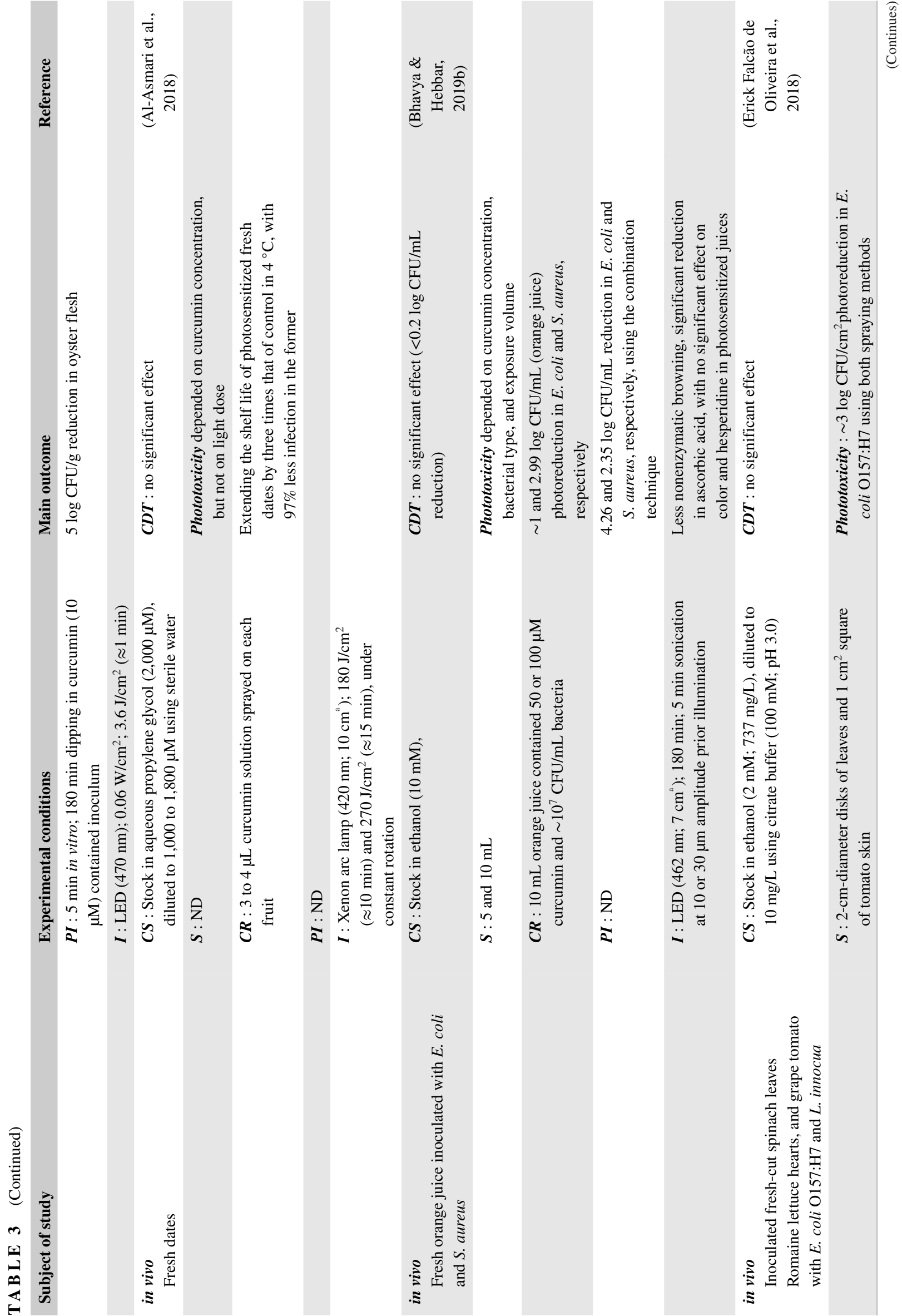

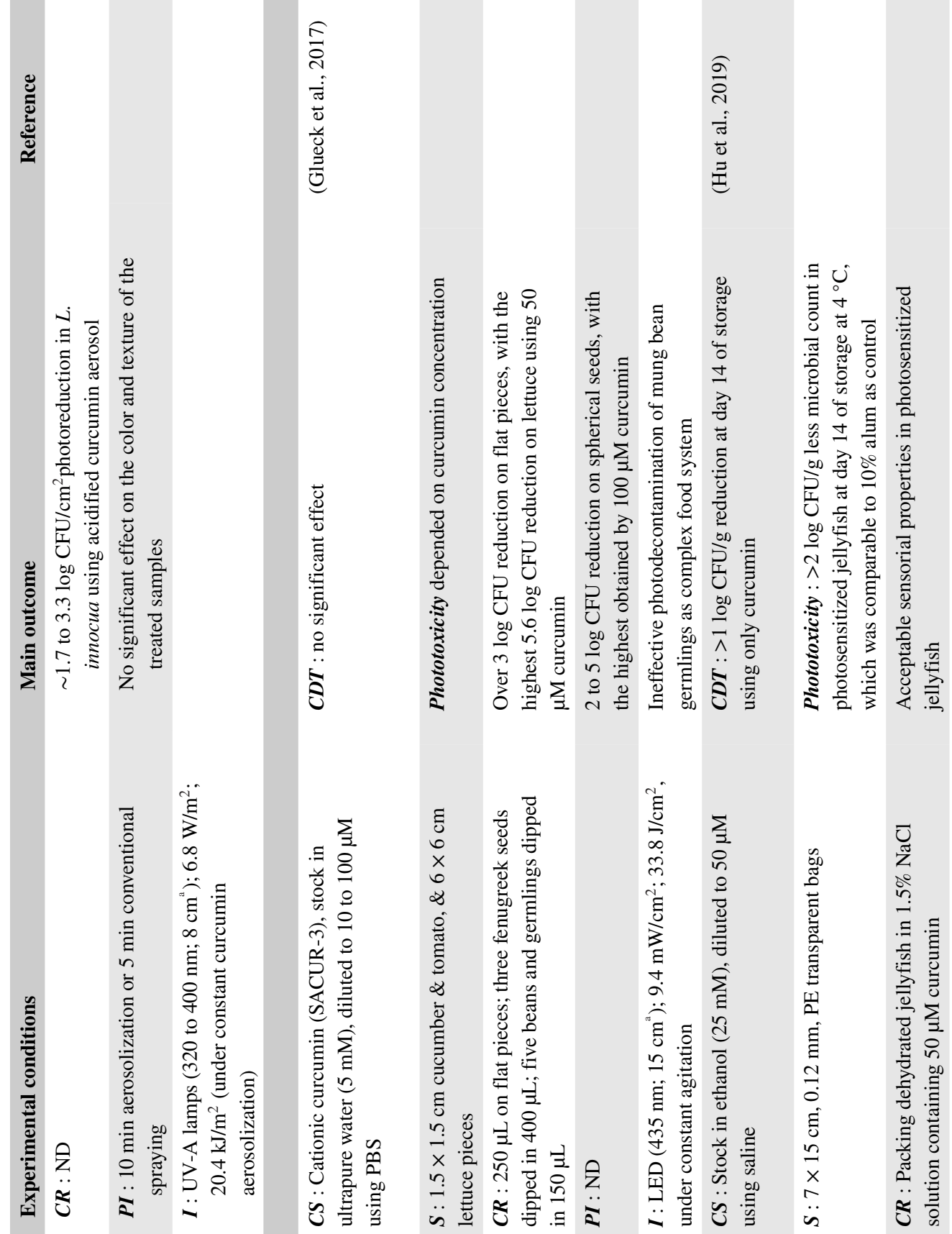

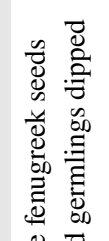

总

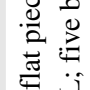

客
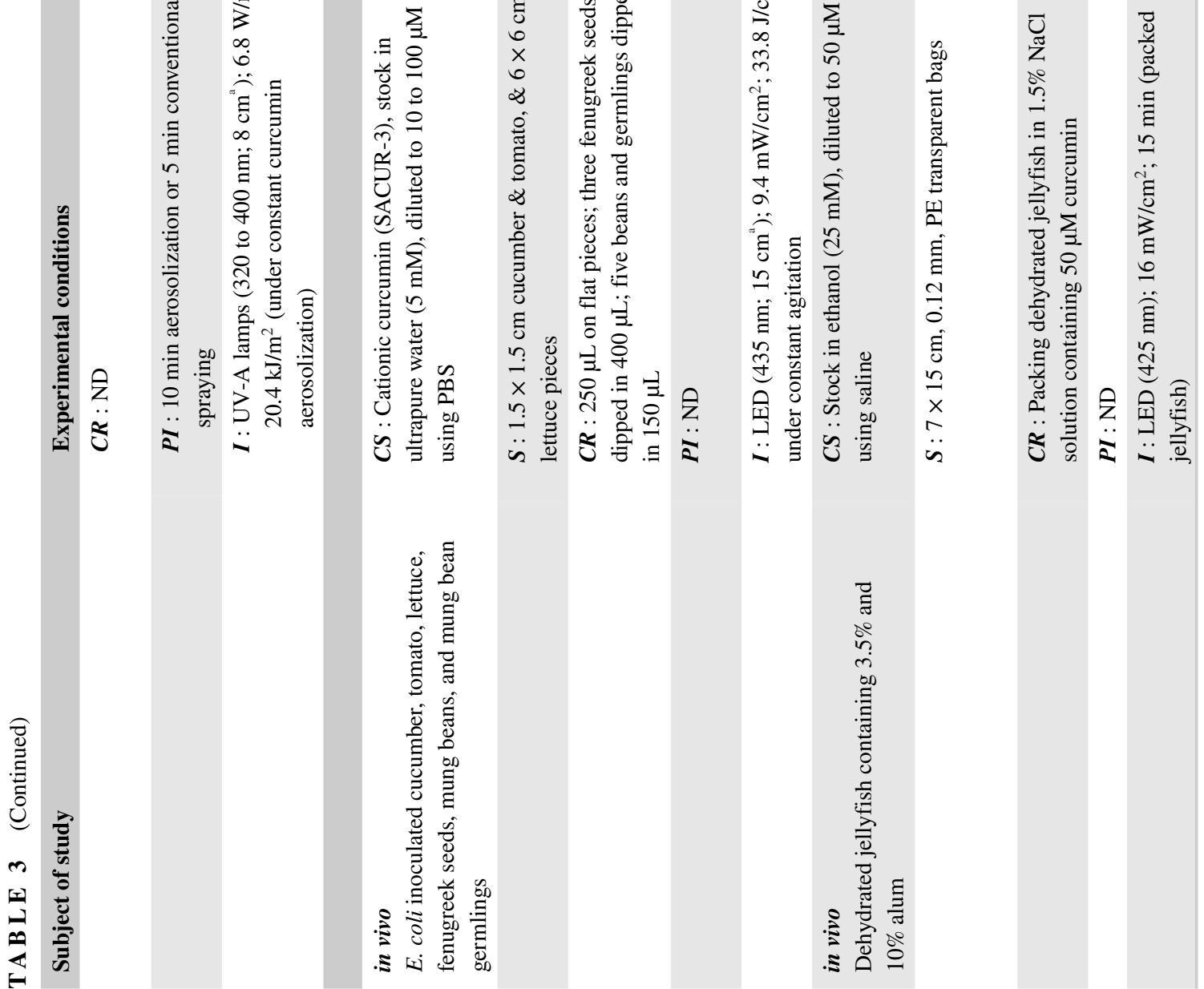


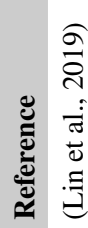

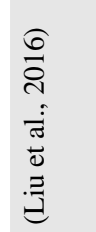

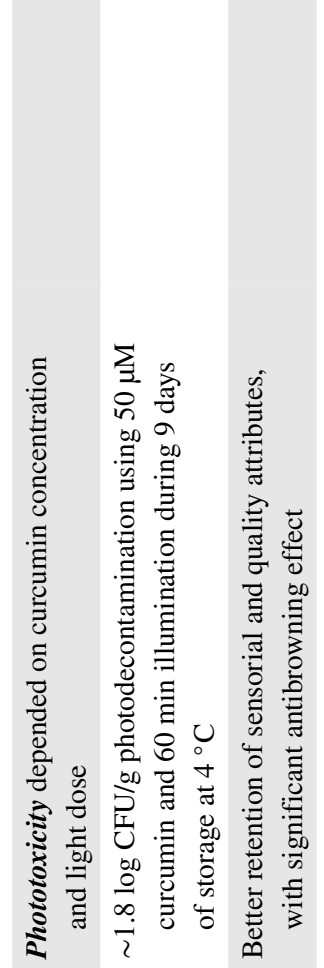

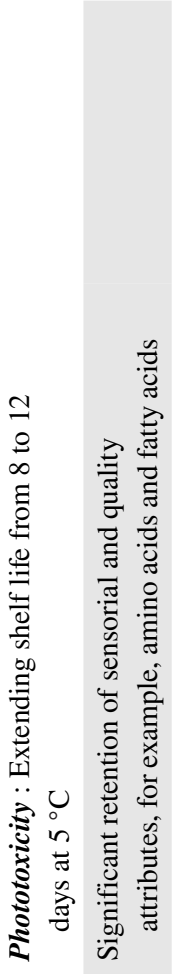
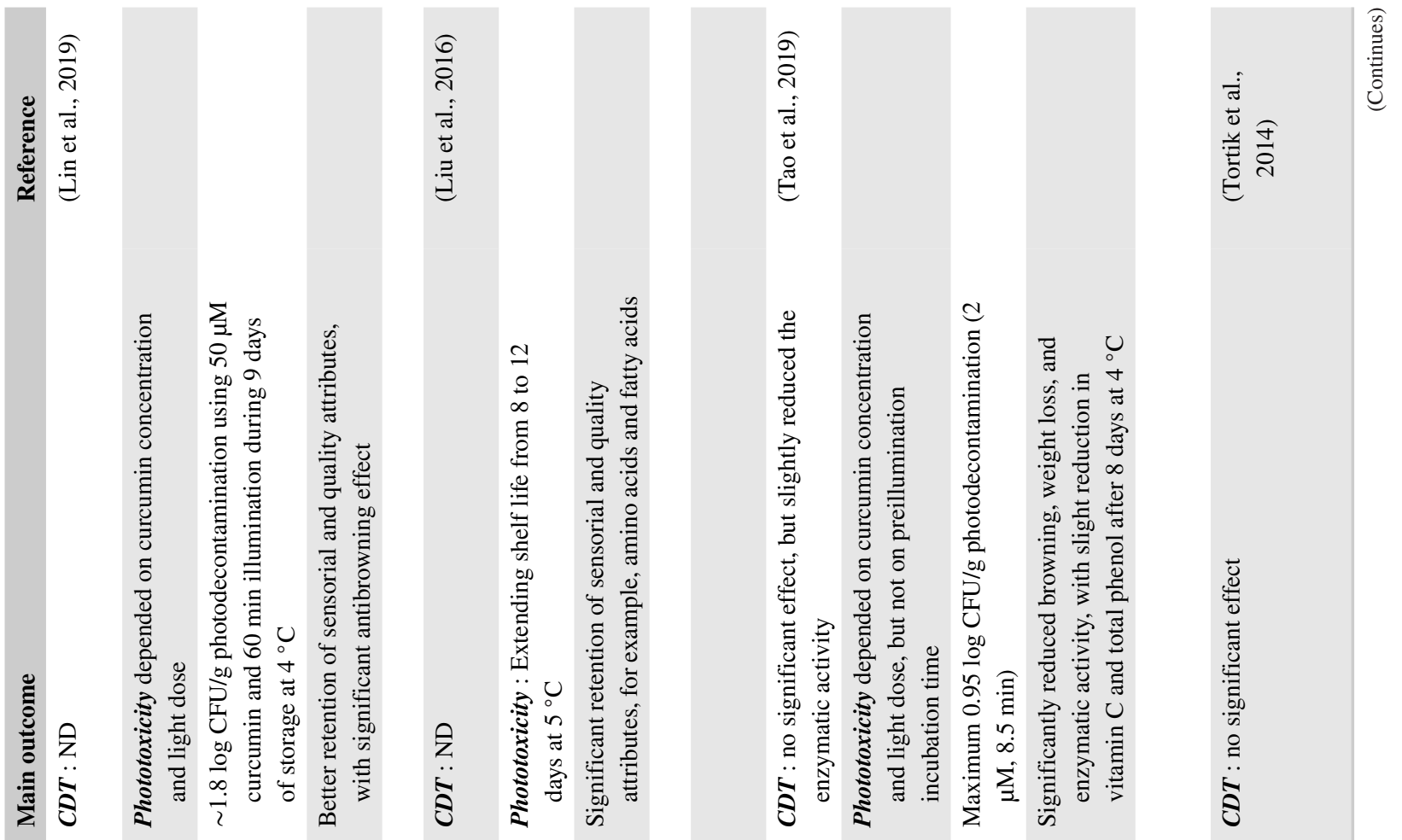

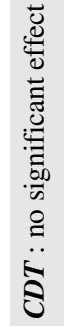
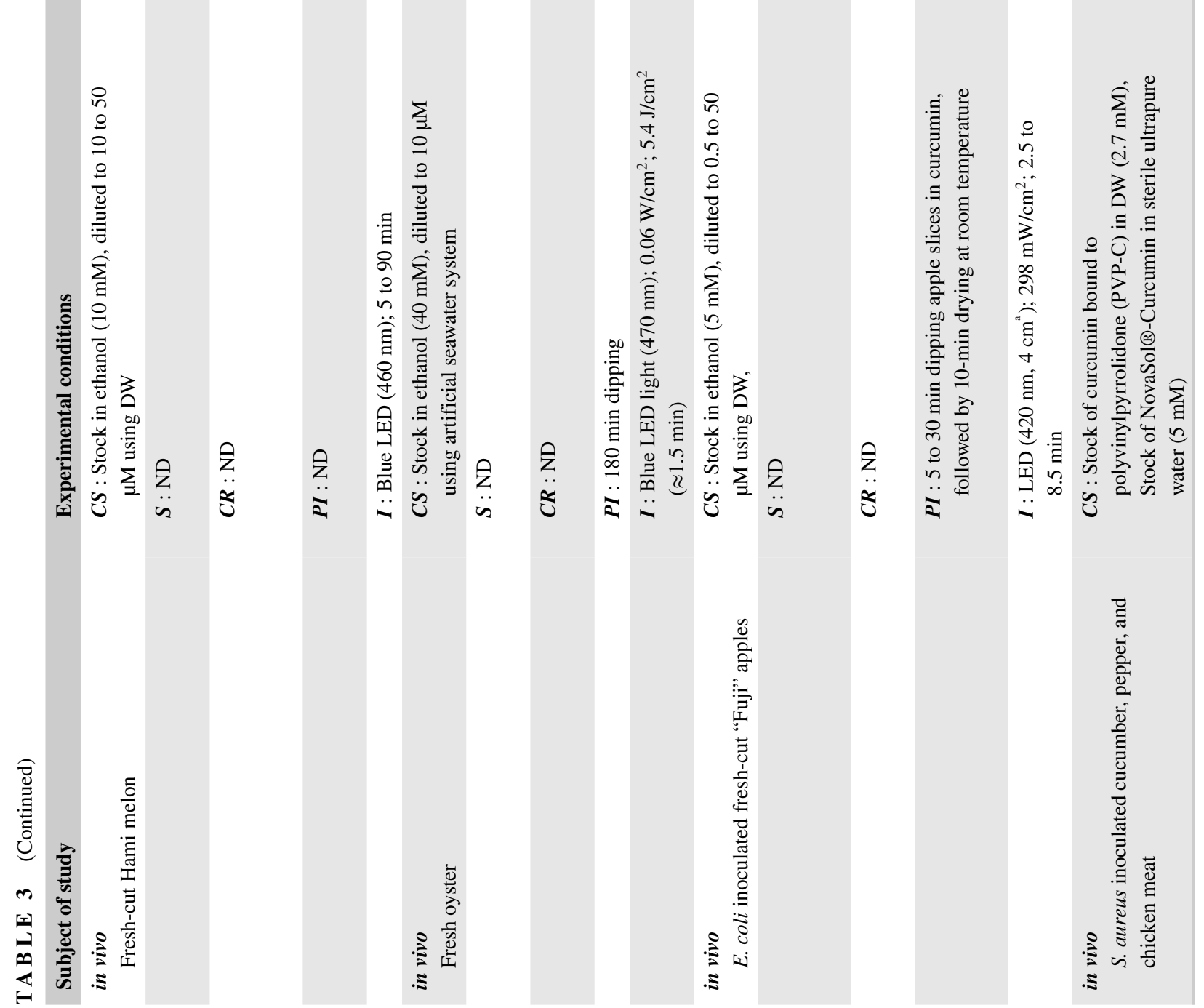

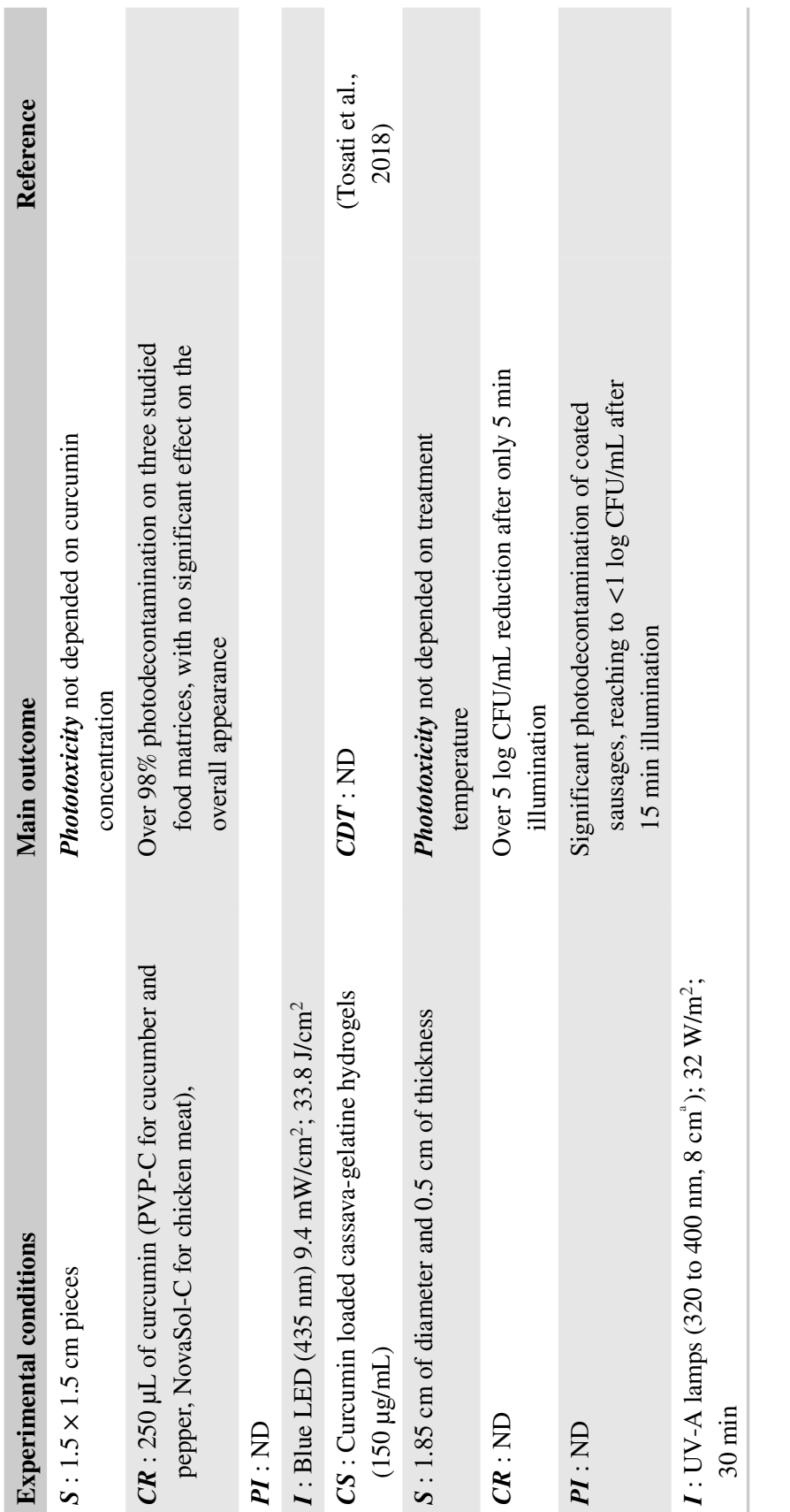

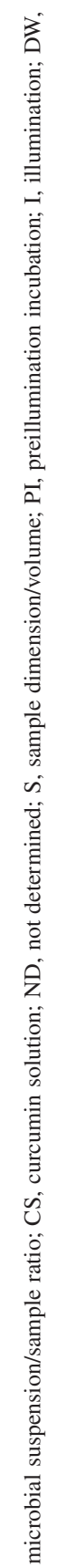

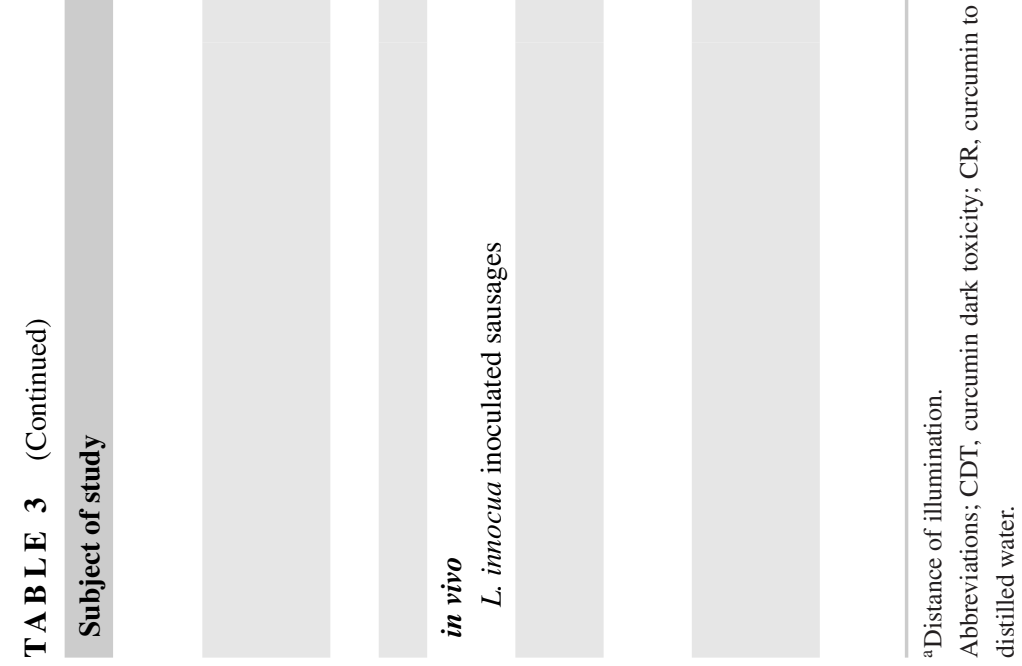




\section{5 | Food applications of curcumin-based photosensitization}

\subsection{1 | In vitro photoinactivation of food-related microorganisms}

The phototoxicity of curcumin as a photosensitizer has extensively been studied against a wide range of microorganisms, which are a challenge in the clinical or food sector. This technology has been recently confirmed as a viable antimicrobial technique in food-related applications showing a broad spectrum efficacy against microorganisms such as Gram-negative and Gram-positive bacteria including Listeria monocytogenes (Ghate et al., 2013), V. parahaemolyticus (Wu et al., 2016), E. coli, Salmonella typhimurium, S. aureus (Penha et al., 2017), L. innocua (Bonifácio et al., 2018), yeasts such as Candida albicans, C. glabrata, and C. dubliniensis (Andrade et al., 2013), and fungal spores including Aspergillus flavus (Temba, Fletcher, Fox, Harvey, \& Sultanbawa, 2016), A. niger, A. flavus, Penicillium griseofulvum, P. chrysogenum, Fusarium oxysporum, C. albicans, and Zygosaccharomyces bailii (AlAsmari, Mereddy, \& Sultanbawa, 2017). The recent publications on the decontamination efficiency of curcumin-based photosensitization are summarized in Table 3. Biofilm formation by various microorganisms is also another area of concern in the food industry, which is a self-produced polymeric matrix enclosing a group of cells with enhanced resistance to antimicrobial treatments compared to planktonic cells (Luksiene \& Brovko, 2013). The effective photoinactivation of these well-structured communities of cells has been clearly demonstrated, for example, $4.9 \log \mathrm{CFU} / \mathrm{mL}$ reduction in L. innocua biofilm using curcumin (Bonifácio et al., 2018). Therefore, identifying the optimum processing conditions against the problematic biofilm producer microorganisms in food production facilities could derive the potential benefits from employing the curcumin-based photosensitization as an alternative to the current chemical sanitizers.

The effectiveness of this treatment could be dependent on several factors such as curcumin concentration and light dosage. Among the reviewed publications, concentration dependency of photoinactivation using curcumin has been reported by Aurum and Nguyen (2019) with ca. 8 log $\mathrm{CFU} / \mathrm{mL}$ reduction in $E$. coli using $1.60 \mathrm{mM}$ curcumin, and using $20 \mu \mathrm{M}$ curcumin led to 5.94 and $5.91 \log \mathrm{CFU} / \mathrm{mL}$ reduction in E. coli and $S$. aureus, respectively (Bhavya \& Hebbar, 2019a), $3.5 \log$ CFU/mL reduction in E. coli DH5 $\alpha$ (Gao et al., 2019), over $3 \log \mathrm{PFU} / \mathrm{mL}$ reduction in murine norovirus 1 (MNV), a seafood- and water-borne virus causing acute gastroenteritis outbreaks (Wu et al., 2015), and over $6.5 \log \mathrm{CFU} / \mathrm{mL}$ reduction in $V$. parahaemolyticus, the major cause of bacterial diarrhea associated with seafood consumption (Wu et al., 2016). The uptake of curcumin by treated microbial cells can be determined using its fluorescence char- acteristics. Studies have shown that a few minutes of incubation resulted in fluorescence detection of curcumin from inside the cellular structures such as mitochondria (Cozzolino et al., 2019; Moustapha et al., 2015). Therefore, considerable cytotoxicity is generally expected from curcumin, which could be further enhanced by reactive oxygen species generation in close vicinity of cellular targets through photosensitization treatment. This was further elucidated by a considerable increase in the level of reactive oxygen species within the treated cells observed through the flow cytometry and confocal laser scanning microscopy (Gao et al., 2019). The increase in reactive oxygen species could contribute to the cell death through destructing cellular membranes, namely, cell, cytoplasmic, and nuclear membranes (Ahn, Kang, Shin, \& Chung, 2012; Maisch et al., 2007). Similarly, Huang et al. (2019) observed an enhancement in bacterial cell inactivation by increasing the curcumin concentration. The results showed over $4 \log \mathrm{CFU} / \mathrm{mL}$ reduction in L. monocytogenes planktonic cells by $0.2 \mu \mathrm{M}$ curcumin $\left(0.54 \mathrm{~J} / \mathrm{cm}^{2}\right.$ [i.e., $5 \mathrm{~min}$ ]), while a complete inactivation was obtained by increasing curcumin concentration to $1.0 \mu \mathrm{M}$ under similar processing conditions. However, processing temperature showed no significant effect on photoinactivation efficiency (Bhavya \& Hebbar, 2019a; Huang et al., 2019). The inoculum concentration of $E$. coli also did not significantly influence the treatment efficiency. The authors, however, observed the considerable inactivation ability of this treatment compared to only LED (light emitting diodes) illumination (Aurum \& Nguyen, 2019).

Theoretically, the activation of photosensitizer and consequently the production of reactive oxygen species is directly related to the light dose. Nonetheless, there is an inconsistency in the reported influence of light dose by the reviewed literature. The dependency on light dose is elucidated in a number of studies (Huang et al., 2019; Penha et al., 2017). Take $S$. aureus as an example, $7.85 \log \mathrm{CFU} / \mathrm{mL}$ curcuminmediated photoinactivation, was achieved by increasing light dose to $100 \mathrm{~J} / \mathrm{cm}^{2}$ (dos Santos et al., 2019). In contrast, some studies have claimed no light dose dependency of curcuminbased photosensitization including ca. 5-log reduction in $L$. moncytogenes using $300 \mu \mathrm{g} / \mathrm{mL}$ curcumin solution at different light doses (Gao \& Matthews, 2020). Another study also showed a relatively similar log reduction of Streptococcus mutans using $8,000 \mu \mathrm{M}$ curcumin at different light doses of 24,48 , and $72 \mathrm{~J} / \mathrm{cm}^{2}$. However, a significant phototoxic effect was observed by increasing the light dose from 24 to 72 $\mathrm{J} / \mathrm{cm}^{2}$ using lower concentrations of curcumin, namely, 2,000 and $4,000 \mu \mathrm{M}$. The population of $S$. mutans was decreased by $30.91 \%$ to $55.98 \%, 33.83 \%$ to $71.07 \%$, and $20.09 \%$ to $26.47 \%$ using curcumin concentrations of 2,000, 4,000, and 8,000 $\mu \mathrm{M}$, respectively. Increasing the curcumin concentration led to a decrease in its phototoxic ability, which could be contributed to the optical quenching that occurred by the excess amount of curcumin present in the environment. This, in turn, 
prevents light to reach the target microorganisms, and therefore, reduces the phototoxic efficiency of the treatment (Paschoal et al., 2013). Furthermore, to find out the impact of food $\mathrm{pH}$ on treatment efficiency, de Oliveira, Tikekar, and Nitin (2018) studied the photoinativation ability of curcumin in its acidified solution ( $\mathrm{pH}$ reduced from 6 to 2.5 using citrate buffer). An enhanced decontamination efficiency in a fairly less illumination time was observed with 5-log and 3-log CFU/mL reduction in E. coli $\mathrm{O} 157: \mathrm{H} 7$ and L. innocua, respectively, after only 2 min illumination. This could be attributed to the effect of citric acid on either the permeability of cellular membrane or the metabolic activity of microbial cells. Therefore, higher curcumin penetration into the microbial cell together with higher cell susceptibility to the treatment could have resulted, which, in turn, causes a higher photoinactivation (de Oliveira et al., 2018). These results, however, favor its application as a preservation technique in foods of acidic environment such as fruit juices.

Interestingly, significant alterations to cell membrane as well as other intracellular components in particular proteins, RNA, and DNA through curcumin-based photosensitization have been established. It was shown that this treatment was able to damage the membrane integrity and permeability, leading to dramatic leakage of intracellular substances (Bhavya \& Hebbar, 2019a; Gao et al., 2019; Jiang et al., 2014). Furthermore, over $90 \%$ sublethal injury was observed in photosensitized E. coli and S. aureus (Bhavya \& Hebbar, 2019a). In addition to cell wall damage and release of cytoplasmic material, notable damage to the genomic DNA and decrease in protein expression was observed in photoinactivated Burkholderia cepacia, an aquatic Gramnegative bacterium, after treatment using $50 \mu \mathrm{M}$ curcumin in combination with $0.4 \%(\mathrm{w} / \mathrm{v})$ Ethylenediaminetetraacetic acid (EDTA) that caused $4 \log \mathrm{CFU} / \mathrm{mL}$ reduction (Hu et al., 2018). This is corroborating the fact that the cell membrane is a key target of reactive oxygen species produced during curcumin-based photosensitization, since microbial survival is dependent on membrane integrity. However, another study suggested that the cytoplasmic DNA and protein were the principal target of curcumin-based photosensitization rather than the outer membrane of L. monocytogenes cells. Furthermore, significant structural alteration and substantially reduced adhesion ability was observed in biofilms under studied conditions of this treatment (Table 3), which was detected through confocal laser scanning microscopy. It was shown that the expression of the virulence genes (inlA, hlyA, and plcA) of the investigated bacterium was markedly downregulated after the treatment, which, in turn, could contribute to a reduction in the adhesive and invasive ability of $L$. monocytogenes. The antibacterial mechanism of the treatment was further elucidated by conducting more experiments such as sodium dodecyl sulfate polyacrylamide gel electrophoresis (SDS-PAGE), DNA extraction and agarose gel electrophoresis, RNA extraction and reverse transcription, and quantitative polymerase chain reaction (qPCR). The analysis of photosensitized-induced damage to genomic DNA and proteins showed the concentration dependency behavior (i.e., the higher curcumin concentration, the higher induced damage). On the other hand, light dosage presented a considerable impact on the DNA damage, while it had insignificant effect on protein damage (Huang et al., 2019). In agreement, a notable damage to the RNA of the photosensitized MNV was observed using RT-PCR analysis, the extent of which was also directly related to the curcumin concentration $(\mathrm{Wu}$ et al., 2015). The evaluation of external and internal structural changes to bacterial cells using scanning and transmission electron microscopy revealed morphology deformation of the cellular surface, but also degradation and leakage of the cytoplasm after curcumin-based photosensitization. Increasing the curcumin concentration and light dose did not show any significant effect on cellular morphology, while the cytoplasm degradation was enhanced by increasing these two parameters (Huang et al., 2019). These studies have shown the nonselective and multitarget attack of the generated reactive oxygen species through curcumin-based photosensitization.

The reported variations in antimicrobial efficacy of curcumin-based photosensitization can obviously be attributed to the differences in the microbial external structure, which is known as the main target of photosensitization (Penha et al., 2017). More resistance of Gram-negative bacteria is due to their outer membrane consisting of proteins with porin function, lipopolysaccharide trimers, and lipoproteins, and therefore presenting a densely packed negative charge (Maisch, Szeimies, Jori, \& Abels, 2004; Nikaido, 1994). Thus, to enhance the uptake of photosensitizers by Gram-negative bacteria, the photosensitizers should be more positively charged. This led to using compounds such as $\mathrm{CaCl}_{2}$ to increase the curcumin penetration into the bacterial cell wall of Gram-negative bacteria, and therefore, enhance the photoinactivation efficiency (Winter, Tortik, Kubin, Krammer, \& Plaetzer, 2013). In comparison, a single cytoplasmic membrane encompasses the Gram-positive bacterial cell, and the exterior is further surrounded by an additional 40 to 80 -nm-thick peptidoglycan wall, with no permeability barrier functionality owing to its relative porosity (Maisch et al., 2004). However, it is hard to relate the susceptibility of bacteria to their Gram nature due to the varied reported results (Ghate et al., 2013), although more susceptibility was seen in Gram-positive bacteria. On the other hand, a cell membrane and a rigid chitin cell wall containing very small pores encompass the fungal cells, namely, yeasts (i.e., unicellular fungi) and molds (i.e., filamentous fungi) (Russell, 2003; Sueoka et al., 2019). In addition to the protective impermeable barrier, the susceptibility of the investigated fungi to the photosensitization treatment (Table 3) could be attributed to the various number of catalase genes as 
an inherent defensive mechanism against reactive oxygen species (Sueoka et al., 2019). It should be mentioned that regarding the food-related spoilage fungi, fungal spore suspensions were mainly examined against the curcumin-based photosensitization. This is due to the high resistance of spores to various antimicrobial techniques, which is generally attributed to their multilayered structures making them impermeable to most chemicals. Temba et al. (2016) employed curcumin-based photosensitization to inactivate A. flavus spores in phosphate buffer saline solution, where up to $3 \log$ $\mathrm{CFU} / \mathrm{g}$ reduction was achieved after $84 \mathrm{~J} / \mathrm{cm}^{2}$ treatment using $25 \mu \mathrm{M}$ curcumin. However, the germination condition of spores is assumed to have an influence on the extent of inactivation phenomenon (Banerjee, Mehta, Dordick, \& Kane, 2012), which needs further investigations. Moreover, the photoinactivation could be affected by the genus or species of the target microorganism, as was observed by Al-Asmari et al. (2017) in a study conducted on five different fungal species. Authors reported $F$. oxysporum and $C$. albicans to be the most susceptible ones, reaching complete photoinactivation under all studied conditions presented in Table 3. In line with those results, Randazzo et al. (2016) reported that photoinactivation of MNV and Feline calcivirus-F9 (FCV) under similar conditions (Table 3 ) led to an almost complete reduction $\left(\sim 5-\log \mathrm{TCID}_{50} / \mathrm{mL}\right)$ in $\mathrm{FCV}$, while only $0.73 \log$ $\mathrm{TCID}_{50} / \mathrm{mL}$ reduction in MNV was obtained. Furthermore, FCV photoinactivation directly depended on curcumin concentration and light dosage, whereas neither of these was demonstrated to affect MNV inactivation (Randazzo et al., 2016).

Other factors influencing the antimicrobial efficacy of the photosensitization treatment include the microbial response to oxidative stress, environmental conditions (Ghate, Kumar, Zhou, \& Yuk, 2016), and the physiological state of microorganisms. The latter particularly influences the accumulation of photosensitizer in the cell, and a better accumulation occurs when bacteria are in the exponential growth phase rather than in the lag phase (Wainwright \& Crossley, 2004). Furthermore, photostability of the applied photosensitizer, which is the main challenge for the majority of natural photosensitizers such as curcumin, could affect the treatment efficiency. The instability and considerable decomposition of curcumin once exposed to the light (i.e., sunlight, UV, and visible light) has been well established (Tønnesen et al., 1986; Tortik, Spaeth, \& Plaetzer, 2014). Consequently, extended illumination times could negatively impact the curcumin phototoxicity against the microorganisms (Aurum \& Nguyen, 2019). However, these shortcomings could be overcome by applying an appropriate delivery vehicle resulting in a better entrance and distribution within the target cells, such as binding curcumin to bovine serum albumin (Cozzolino et al., 2019). This, in turn, increases the interaction of produced reactive oxygen species with a variety of target cellular structures. However, a rise in phototoxic activity of curcumin against Gram-negative and Gram-positive bacteria was noted by dissolving it in aqueous dimethyl sulfoxide and polyethyleneglycol, compared to being dissolved in other investigated surfactants or entrapping in cyclodextrin and liposomes (Haukvik et al., 2009).

The variable composition of the microbial cell walls, namely, the presence and the amount of charged residues and cations, contributed to the degree of microbial susceptibility to the treatment. To be more explicit, the binding capacity and the uptake of photosensitizer by the microbial cells are significantly influenced by the electrostatic interactions. Furthermore, some microorganisms produce pigments that could quench the illuminated light and, in turn, protect the microorganism from the phototoxic effects of this treatment (Kreitner et al., 2001). The observed differences in the literature could also be attributed to the differences in the experimental conditions (as are presented in Table 3) such as the ratio of photosensitizer solution to the microbial suspension, the photosensitizer solvent (as some solvents may enhance the affinity toward the microorganisms leading to better photoinactivation), and the light source. By and large, studies have shown that an enhancement in photosensitizer concentration, using cationic photosensitizers, and conjugating photosensitizer to antimicrobial peptides may result in better binding to target cells and increase the photodecontamination efficiency.

\subsection{2 | Photoinactivation of microorganisms in food}

Photosensitization as a viable and safe preservation technique in the food industry, in particular for fresh fruits and vegetables, has been recently investigated and promising results have been obtained using different natural photosensitizers such as Na-chlorophyllin (Paskeviciute, Zudyte, \& Luksiene, 2018) and hypericin (Aponiene, Paskeviciute, Reklaitis, \& Luksiene, 2015). The efficacy of curcumin-based photosensitization to decontaminate various foods and consequently to increase their shelf life has also been established by a number of studies summarized in Table 3. Photosensitization is generally considered as a surface decontamination technique due to the lower penetration ability of blue light region, where the maximum absorption of curcumin falls in $\sim 430 \mathrm{~nm}$. Hence, it is mostly to be used for decontamination of surfaces of either food or processing facilities. As an illustration, spraying the acidified curcumin $(10 \mathrm{mg} / \mathrm{L}, \mathrm{pH} 3.0)$ on lettuce, spinach, and tomato inoculated with E. coli $\mathrm{O} 157: \mathrm{H} 7$ and $L$. innocua and 5 min UV-A illumination (i.e., $20.4 \mathrm{~kJ} / \mathrm{m}^{2}$ ) led to $\sim 3 \mathrm{log}$ $\mathrm{CFU} / \mathrm{cm}^{2}$ reduction with no adverse impact on the color and texture of the produce. Two spraying techniques were used, viz. aerosolization and conventional spray atomization, having no significant difference in photoinactivation. In spite of that, the aerosolization resulted in a uniform deposition with 
10-time lower volume of the photosensitizer on the surface of the produce. The uniformity and lack of coalescence was proven to be more effective than conventional spraying system (de Oliveira, Tosati, Tikekar, Monteiro, \& Nitin, 2018). Moreover, aerosol-based deposition causes an increase in the contact between microbial cells and photosensitizer, which is due to very fine aerosol particles presenting gas-like behavior (Oh, Gray, Dougherty, \& Kang, 2005). It was also shown that this treatment is able to effectively decontaminate the wash water (during simulated spinach and tomato washing) and the surface of fresh produce from $E$. coli and $L$. innocua by over 5$\log \mathrm{CFU} / \mathrm{mL}$ in the presence of high chemical oxygen demand (COD; $1,000 \mathrm{mg} / \mathrm{L}$ ). Furthermore, the possibility of decreasing cross contamination of washed spinach leaves by the wash water was observed, where 150 and $6 \mathrm{CFU} / \mathrm{cm}^{2}$ of $E$. coli and 1,000 and $2 \mathrm{CFU} / \mathrm{cm}^{2}$ of L. innocua were detected on the washed spinach leaves after conventional and photosensitized washing, respectively (de Oliveira et al., 2018). Therefore, its ability to reduce the occurrence of cross contamination on the washed and ready-to-eat fruits and vegetables can potentially lower the risk of food-borne diseases, which is a challenging area of concern in the food industry. Hence, these findings indicate that curcumin-based photosensitization could be considered as a potential alternative to the conventional sanitizing agents and treatments, resulting in a safer washed horticultural produce for the consumers.

A technical aspect of application of curcumin-based photosensitization in food industry is the impact of food geometry on decontamination efficiency. In this regard, Glueck et al. (2017) reported a higher photodecontamination in flat samples as compared to the spherical and more complex geometries. Authors concluded that rotation during illumination is required for spherical samples (e.g., mung beans) to gain a satisfactory result. However, two-dimensional light source demonstrated to be ineffective for more complex geometries such as mung bean germlings with $\sim 1 \log$ CFU reduction in $E$. coli regardless of the curcumin concentration used. This was related to the uneven surface of the germinated seeds, for which the rotation of light source or developing a threedimensional light source was suggested. Among the factors influencing the efficacy of photodecontamination of foods, curcumin concentration (Glueck et al., 2017; Wu et al., 2015) and light dose has shown to have a fairly positive effect. The light dosage dependency was observed in photodecontamination of the $E$. coli inoculated grapes, where an increase in light dose to $36.3 \mathrm{~J} / \mathrm{cm}^{2}$ gave rise to the highest reduction of $2.40 \log \mathrm{CFU} / \mathrm{mL}$ using $1.6 \mathrm{mM}$ curcumin (Aurum \& Nguyen, 2019). Another study also demonstrated the concentration dependency behavior of curcumin-based photosensitization, where $1,400 \mu \mathrm{M}$ curcumin $\left(180 \mathrm{~J} / \mathrm{cm}^{2}\right)$ exhibited to be efficient in delaying mold spoilage and, in turn, enhancing the shelf life of fresh dates with no adverse impact on the physicochemical properties. The extension in shelf life was, however, dependent on storage temperature, that is, shelf life of treated dates stored at 30 and $4{ }^{\circ} \mathrm{C}$ was increased two and three times to that of the untreated ones (i.e., control), respectively (AlAsmari, Mereddy, \& Sultanbawa, 2018). Photodecontamination of inoculated orange juice also showed to be dependent on curcumin concentration in case of S. aureus with the highest reduction of $2.99 \log \mathrm{CFU} / \mathrm{mL}$ using $100 \mu \mathrm{M}$ curcumin. No concentration dependency was observed in E. coli decontamination with $\sim 1 \log \mathrm{CFU} / \mathrm{mL}$ reduction using either 50 or $100 \mu \mathrm{M}$ curcumin (Bhavya \& Hebbar, 2019b). This is corroborating with the aforementioned fact that the genus type of microorganisms also affects the treatment efficiency. Similar findings in concentration and light dosage dependency were obtained for the E. coli inoculated Fuji apple slices (Table 3), with no significant effect of preillumination soaking time. It was also shown that increasing the light dosage led to less weight loss and browning occurrence (Tao et al., 2019). In agreement, Lin et al. (2019) concluded that increasing the curcumin concentration to $50 \mu \mathrm{M}$ and illumination time to $60 \mathrm{~min}$ resulted in further reduction in total aerobic microorganism population in fresh-cut Hami melon. However, it was shown that concentrations higher than the optimum (i.e., 50 $\mu \mathrm{M})$ presented less efficiency due to saturation as well as aggregation of curcumin (Glueck et al., 2017). On the other hand, Gao and Matthews (2020) claimed no significant effect of light dosage as well as incubation time on photosensitization efficiency. Also, light doses of $32.1 \mathrm{~kJ} / \mathrm{cm}^{2}$ or higher showed no significant color change of the skin, compared to the control. This study indicated that the curcumin-based photosensitization exhibited an equivalent or even better decontamination efficiency compared to the $300 \mu \mathrm{g} / \mathrm{mL}$ peracetic acid as the commercial antimicrobial in poultry industry (Gao $\&$ Matthews, 2020). Curcumin-based photosensitization was also capable of significant reduction in aflatoxin $\mathrm{B}_{1}$ production during storage of A. flavus inoculated maize $(82.4 \mu \mathrm{g} / \mathrm{kg})$ as compared to the untreated maize with $305.9 \mu \mathrm{g} / \mathrm{kg}$ aflatoxin (Temba et al., 2019). Generally, an insignificant antimicrobial effect was observed by either curcumin or light only in the reviewed literature (Table 3), suggesting the importance of the combination of photosensitizer and light to elicit the desired antimicrobial effect.

The use of augmentation strategy to improve the decontamination efficiency of curcumin-based photosensitization in orange juice was investigated by integrating it with sonication. Results showed a decrease of 2.35 and $4.26 \mathrm{log}$ $\mathrm{CFU} / \mathrm{mL}$ (orange juice) in $S$. aureus and E. coli populations, respectively. Sonication of the inoculated orange juice prior to photosensitization exhibited no additive effect on photodecontamination of $S$. aureus, while it demonstrated significantly higher inactivation in E. coli compared to the individual treatments. Having said that, sonication alone showed a considerable potential in E. coli inactivation, compared to S. aureus (Bhavya \& Hebbar, 2019b). The differences in 
microbial susceptibility are obviously due to the existing structural differences. Another study evidenced that curcumin-based photosensitization of $3.5 \%$ alum contained jellyfish resulted in shelf life extension of up to 1 month at $4{ }^{\circ} \mathrm{C}$, which was comparable to the $10 \%$ alum in dehydrating brine as the conventional preservative (Hu et al., 2019). This exhibited the potential of this treatment as a decontamination and preservation technique to reduce the required amount of chemical preservatives in food products. Furthermore, 5-min illumination of the pasteurized Coalho cheese in the presence of curcumin led to $4.34 \log \mathrm{CFU} / \mathrm{g}$ reduction in microbial count. It showed an inability to decontaminate the unpasteurized Coalho cheese (an insignificant reduction of $\sim 0.5$ $\log$ CFU/g) (dos Santos et al., 2019), which is clearly due to the high microbial loads. This is in contrast to the results by Aurum and Nguyen (2019) reporting nondependency of the treatment on inoculum concentration. However, this could be due to the differences in experimental models (i.e., in vitro and in vivo) as well as the curcumin type being used. With respect to the latter point, treating high protein foods such as cheese with pure curcumin would not be advisable, due to the tendency of curcumin to bind with proteins. This leads to its less availability as a photosensitizer toward microorganisms. Therefore, a water soluble curcumin salt was used as the photosensitizer in the study on Coalho cheese (dos Santos et al., 2019).

Generally, food products are exposed to the produced reactive oxygen species during curcumin-based photosensitization, which is likely to impose oxidative damage to the treated food and affect its safety. Among the recent publications, Gao et al. (2019) conducted a cellular toxicological study on photosensitized oysters inoculated with $E$. coli DH5 $\alpha$. Results demonstrated no cytotoxicity occurrence in treated oysters, and were therefore considered as safe for consumption. Furthermore, the sensorial properties of the treated oysters were not adversely affected by the applied curcumin concentration (i.e., $20 \mu \mathrm{M}$ ). However, further research is needed to validate the safety of this treatment to be employed on foods.

To achieve a successful preservation treatment based on photosensitization, different factors associated with the food matrix (e.g., surface properties, acidity, and water activity) and processing conditions (e.g., photosensitizer concentration, wavelength, light dose, temperature) should be considered. However, an in-depth discussion of the food-related parameters can be found elsewhere (Ghate, Zhou, \& Yuk, 2019). Take acidity as an example, the efficacy of a photosensitizer is generally determined by two isoelectric points, namely, the whole cell isoelectric point and the photosensitizer isoelectric point. The former determines the charge on the microbial cell (Jucker, Harms, \& Zehnder, 1996), and the latter affects the photosensitizer net charge. Therefore, the electrostatic attraction and subsequent attachment of photosensitizer to the target microorganism, and, in turn, the suc- cess of the photosensitization treatment could be affected by the $\mathrm{pH}$ of the treated food associated with the two isoelectric points (Ghate et al., 2019). It is also noteworthy to mention that heterogeneous distribution of the light energy on the food surface due to the uneven exposure to the light could result in a lower efficiency compared to the in vitro findings. This issue, however, can be overcome by a proper design of the treatment tunnel to have the homogeneous light exposure on the maximum surface areas of the food. In addition, decontamination of liquids such as fruit juices could be achievable by a proper tubular or planar design to reduce the thickness of the product to be treated, with an appropriate transparent material to not interfere with the required light for photo inactivation. Furthermore, as presented in Table 3, the differences in experimental conditions such as the curcumin application method (e.g., spraying, dipping), the dimensions, or the volume of the food being treated, illumination while being soaked or not, could contribute to the outcome of the treatment. More research is therefore needed to clarify the influencing operating parameters on the photodecontamination efficiency to address the observed variance issue in the literature. The reviewed literature has, however, shown the efficacy of curcumin-based photosensitization in enhancing the shelf life of food through the inactivation of spoilage and pathogenic microorganisms. Hence, more work is required to further understand the critical parameters influencing the treatment effectiveness, which could be beneficial in commercializing this green preservation technique.

\subsection{3 | Photosensitization and its effect on quality and sensorial properties of food}

Maintaining the quality attributes (e.g., appearance, color, nutritional properties) of foods is an obvious criterion of an effective preservation technique. Taking phenolics and anthocyanins as examples, which tend to accumulate in epidermal and cortex tissues of fruits and vegetables, the possibility of adverse impacts of photosensitization on their concentration and bioaccessibility is of concern due to their light sensitivity. However, it has also been reported that illuminating the fresh produce may result in enhancing the formation and accumulation of different secondary metabolites, which is dependent on the types of fruits and vegetables (Darko, Heydarizadeh, Schoefs, \& Sabzalian, 2014). According to the reviewed studies, curcumin-based photosensitization exhibited a protective impact on composition (e.g., amino acids, fatty acids), quality, and sensorial properties (e.g., color, flavor, water content, firmness) with a notable antibrowning effect on the treated foods (Bhavya \& Hebbar, 2019b; Hu et al., 2019; Liu et al., 2016). In the case of reduced alum (3.5\%) jellyfish, photosensitization exhibited less organoleptic stability, compared to the conventional $10 \%$ alum treatment (Hu et al., 2019). 
Regarding the nutritional properties, no adverse influence on the composition of the photosensitized jellyfish was observed (Hu et al., 2019). Liu et al. (2016) demonstrated a notable protective effect of curcumin-based photosensitization on flavor compounds, free amino acids, fatty acids (namely, total saturated fatty acids, monounsaturated lipids, and polyunsaturated fatty acids), and lipids of oysters through 8 days of storage. Free amino acid content of oysters is important from both taste and nutritional aspects, where the total content was 243.30 in untreated and $813.02 \mathrm{mg} / 100 \mathrm{~g}$ in treated oysters after 8 days of storage. In addition, a higher quantity of the analyzed fatty acids and lipids, and in particular $20.57 \%$ higher polyunsaturated fatty acids (i.e., docosahexaenoic and eicosapentaenoic acids) was observed in photosensitized oysters. Less thiobarbituric acid and free fatty acid contents also indicated less fatty acid oxidation and lipid degradation, respectively, in photosensitized oysters (Liu et al., 2016). Moreover, total value of basic nitrogen (TVBN) is considered as a shelf life indicator of the seafood products, and end of shelf life is determined when TVBN reaches the $30 \mathrm{mg} / 100 \mathrm{~g}$ (Cao, Xue, Liu, \& Xue, 2009). Significantly lower TVBN values were observed in the photosensitized jellyfish (Hu et al., 2019), and oysters, with the latter having $\sim 15 \mathrm{mg} / 100 \mathrm{~g}$ at day 12 of storage ( $63 \%$ lower than untreated oysters) (Liu et al., 2016). This, in turn, indicates the potential of curcumin-based photosensitization in retarding seafood degradation during storage (Choi, Shin, Cheong, Jin, \& Park, 2013).

Furthermore, curcumin-based photosensitization gave rise to better color retention throughout the storage period of treated foods such as grapes (Aurum \& Nguyen, 2019), freshcut Hami melons (Lin et al., 2019), orange juice (Bhavya \& Hebbar, 2019b), and Pacific oysters (Liu et al., 2016). The illumination of curcumin-treated food products gave rise to the loss of yellowness obtained by the photosensitizer, as observed in chicken skin (Gao \& Matthews, 2020). This is mainly due to either photodegradation or oxidation of curcumin. The former produces colorless compounds such as ferulic acid, vanillin, and other small phenols (Priyadarsini, 2009; Tønnesen et al., 1986). However, the latter occurs through the produced reactive oxygen species that oxidizes the curcumin (Gao \& Matthews, 2020). The working concentrations of curcumin in food applications are very low (Table 3) and at this concentration should not add any taste or odor to the treated foods. However, this needs to be assessed in further studies, as there is no reported data in the literature. Interestingly, curcumin-based photosensitization also showed a notable antibrowning impact on the treated foods including fresh-cut Fuji apples (Tao et al., 2019), fresh-cut Hami melons (Lin et al., 2019), and orange juice (Bhavya \& Hebbar, 2019b). It should be mentioned that a considerable reduction in peroxidase and polyphenol oxidase by $48 \%$ and $51 \%$, respectively, was demonstrated by Tao et al. (2019), enzymes that are responsible for the browning phe- nomenon. The enzyme inhibition study was, however, conducted on a crude enzyme solution, which could vividly differ from the enzyme reduction ability of this treatment in a real food matrix. Nevertheless, this could be contributed to the considerable antibrowning effect of photosensitization treatment, even using very low concentrations of curcumin (Tao et al., 2019). Moreover, Bhavya and Hebbar (2019b) observed a reduction in cloudiness of the photosensitized orange juice, where adding sonication to the photosensitization treatment adversely affected the color, cloudiness, and nonenzymatic browning of orange juice (Bhavya \& Hebbar, 2019b). This is obviously attributed to the oxidation reactions and molecular degradation induced by the cavitation phenomenon (Tiwari \& Mason, 2012). A varied trend was, however, observed in reported values of total soluble solids during storage. A slight increase was observed in photosensitized grapes (Aurum \& Nguyen, 2019), which was attributed to the water loss occurrence (Valverde et al., 2005) as well as the hydrolytic enzyme activities (Nabifarkhani, Sharifani, Daraei Garmakhany, Ganji Moghadam, \& Shakeri, 2015). In contrast, a significant decrease in total soluble solids was observed in the photosensitized fresh-cut Hami melons, which was attributed to the photosensitization influence on microbial respiration (Lin et al., 2019).

Weight loss was significantly reduced in photosensitized foods including grapes (Aurum \& Nguyen, 2019), fresh-cut Fuji apples (Tao et al., 2019), and fresh-cut Hami melon (Lin et al., 2019). This was related to less water loss due to less textural degradation (Aurum \& Nguyen, 2019), antibacterial effect (Lin et al., 2019), as well as inactivation of enzymes involved in the respiratory chain by the reactive oxygen species generated during curcumin-based photosensitization (Tao et al., 2019). Firmness of the treated foods was not significantly affected by photosensitization. Although a slight reduction was observed in treated grapes (Aurum \& Nguyen, 2019), higher firmness values were reported for the treated fresh-cut Hami melons (Lin et al., 2019). The latter was suggested to be related to the antibacterial effect of photosensitization treatment resulting in less microbial growth and activity (Lin et al., 2019). However, photosensitization treatment might affect the textural properties of the high collagen food products such as jellyfish through the probable occurrence of collagen cross-linking due to photooxidation induced by the generated reactive oxygen species (Choi et al., 2013). A slight reduction in textural characteristics (i.e., springiness, cohesiveness, hardness, and chewiness) of the photosensitized jellyfish was observed, which was still in an acceptable range compared to the control (10\% alum) (Hu et al., 2019). Textural properties of oysters were not negatively influenced by curcumin-based photosensitization (Liu et al., 2016).

However, a few negative impacts on the contents of total phenolic and ascorbic acid in photosensitized fresh-cut apple and orange juice were reported (Bhavya \& Hebbar, 2019b; 
Tao et al., 2019). A 5\% reduction in ascorbic acid was observed in photosensitized grapes (Aurum \& Nguyen, 2019), while a notable reduction was observed in photosensitized orange juice by $65 \%$ (Bhavya \& Hebbar, 2019b). This could be attributed to the generation of reactive oxygen species (i.e., free radicals) through photosensitization and therefore inducing the oxidation reactions in susceptible compounds such as vitamin C (Bhavya \& Hebbar, 2019b). Using curcumin-based photosensitization treatment exhibited no significant effect on total flavonoid and hesperidin contents; the latter is the wellknown phenolic compound of orange juice, although a slight decrease was observed in the total phenolic content (Bhavya \& Hebbar, 2019b). Another point that should be elucidated in the case of photosensitization treatment is whether the naturally occurring components within the treated foods play a negative or positive role in the efficiency of the treatment. An example of a negative could be photodegradation of these components, resulting in undesirable organoleptic impacts through lipid oxidation (Cardoso, Libardi, \& Skibsted, 2012). The phototoxicity of compounds such as gallic acid (Cossu et al., 2016; Nakamura et al., 2012), riboflavin (Josewin, Ghate, Kim, \& Yuk, 2018), and caffeic acid (Gilbert, Alborzi, Bastarrachea, \& Tikekar, 2018) have been demonstrated, which could be naturally found in foods and may synergistically affect the photosensitization efficiency, although it depends on the applied illumination wavelength. What is more, the probable rise in temperature due to the radiant energy of light is inevitable that could adversely affect the treated foods, and has not been referred to in the literature. This temperature increase could result in further water loss of the treated food, and as a consequence, negatively influence its overall appearance as well as the organoleptic properties.

\section{5 | CONCLUSION}

The priority of all food producers is to prolong the shelf life of foods with reference to safety, organoleptic, and nutritional properties. Various preservation technologies have been introduced to the food industry; however, they are still challenged from some drawbacks such as being time-consuming, expensive, lack of efficacy against resistant microorganisms and spores, and occurrence of adverse effects on quality criteria (e.g., color, texture, bioactive compounds). Photosensitization has recently gained attention benefiting from the use of naturally occurring photosensitizers and light. The reactive oxygen species produced through photoexcitation of a natural photosensitizer attack the microorganisms nonselectively and provide a microbial resistance-free technique. Curcumin has shown promising phototoxicity against a range of "problematic" microorganisms in the food industry. Its applicability has been further investigated in various food products, either fresh or processed, and exhibited successful delays in spoilage with no adverse effects on the organoleptical quality of the treated foods. Moreover, designing an efficient and food compatible nanodelivery system can improve not only the solubility and stability of curcumin in aqueous environments, but also its cellular uptake and therefore photodecontamination efficiency. It should be mentioned that the delivery system should be cost-effective and easy to be adopted by the industry. Illumination might also increase the formation of different metabolites such as antioxidants as a result of light stress, which can further help with preserving the fresh fruits and vegetables. On the other hand, photodegradation of naturally occurring components in treated foods might result in undesirable organoleptic effects through lipid oxidation. Therefore, it should be elucidated whether the naturally occurring components within the treated foods play a negative or positive role in determining the effectiveness of photosensitization. The possibility of adverse effects on the composition, bioaccessibility and subsequent bioavailability of nutrients and other bioactive compounds in the treated foods must also be investigated. In spite of curcumin showing promising phototoxic activity, more cost-effective photosensitizers are required to successfully implement this treatment in the food and beverage industry.

\section{ACKNOWLEDGMENT}

Maral Seidi Damyeh acknowledges the support from Australian Government by the Research Training Program Scholarship for her doctorate studies at the University of Queensland (Brisbane, Australia). The authors would also like to thank Horticulture Innovation Australia Limited through the HN15001 Naturally Nutritious project.

\section{AUTHOR CONTRIBUTIONS}

Maral Seidi Damyeh prepared and wrote the manuscript. Ram Mereddy, Michael E. Netzel, and Yasmina Sultanbawa corrected, revised, and improved the manuscript.

\section{CONFLICTS OF INTEREST}

The authors have no conflicts of interest to declare, financial, or otherwise.

\section{ORCID}

Maral Seidi Damyeh

https://orcid.org/0000-0003-3517-4521

Yasmina Sultanbawa

https://orcid.org/0000-0002-6315-5996

\section{REFERENCES}

Abdou, E. S., Galhoum, G. F., \& Mohamed, E. N. (2018). Curcumin loaded nanoemulsions/pectin coatings for refrigerated chicken fillets. Food Hydrocolloids, 83, 445-453. 
Aggarwal, B. B., \& Sung, B. (2009). Pharmacological basis for the role of curcumin in chronic diseases: An age-old spice with modern targets. Trends in Pharmacological Sciences, 30(2), 85-94.

Ahn, J.-C., Kang, J.-W., Shin, J.-I., \& Chung, P.-S. (2012). Combination treatment with photodynamic therapy and curcumin induces mitochondria-dependent apoptosis in AMC-HN3 cells. International Journal of Oncology, 41(6), 2184-2190.

Akram, M., Shahab-Uddin, A. A., Usmanghani, K., Hannan, A., Mohiuddin, E., \& Asif, M. (2010). Curcuma longa and curcumin: A review article. Romanian Journal of Biology - Plant Biology, 55(2), 65-70.

Al-Asmari, F., Mereddy, R., \& Sultanbawa, Y. (2017). A novel photosensitization treatment for the inactivation of fungal spores and cells mediated by curcumin. Journal of Photochemistry and Photobiology B: Biology, 173, 301-306.

Al-Asmari, F., Mereddy, R., \& Sultanbawa, Y. (2018). The effect of photosensitization mediated by curcumin on storage life of fresh date (Phoenix dactylifera L.) fruit. Food Control, 93, 305-309.

Andrade, M. C., Ribeiro, A. P. D., Dovigo, L. N., Brunetti, I. L., Giampaolo, E. T., Bagnato, V. S., \& Pavarina, A. C. (2013). Effect of different pre-irradiation times on curcumin-mediated photodynamic therapy against planktonic cultures and biofilms of Candida spp. Archives of Oral Biology, 58(2), 200-210.

Ansari, M., Ahmad, S., Kohli, K., Ali, J., \& Khar, R. (2005). Stabilityindicating HPTLC determination of curcumin in bulk drug and pharmaceutical formulations. Journal of Pharmaceutical and Biomedical Analysis, 39(1-2), 132-138.

Aponiene, K., Paskeviciute, E., Reklaitis, I., \& Luksiene, Z. (2015). Reduction of microbial contamination of fruits and vegetables by hypericin-based photosensitization: Comparison with other emerging antimicrobial treatments. Journal of Food Engineering, 144, 29 35 .

Aponiene, K., Serevičius, T., Luksiene, Z., \& Juršènas, S. (2017). Inactivation of bacterial biofilms using visible-light-activated unmodified $\mathrm{ZnO}$ nanorods. Nanotechnology, 28(36), 365701.

Araiza-Calahorra, A., Akhtar, M., \& Sarkar, A. (2018). Recent advances in emulsion-based delivery approaches for curcumin: From encapsulation to bioaccessibility. Trends in Food Science \& Technology, 71, 155-169.

Arnason, J., Guerin, B., Kraml, M., Mehta, B., Redmond, R., \& Scaiano, J. (1992). Phototoxic and photochemical properties of sanguinarine. Photochemistry and Photobiology, 55(1), 35-38.

Aurum, F. S., \& Nguyen, L. T. (2019). Efficacy of photoactivated curcumin to decontaminate food surfaces under blue light emitting diode. Journal of Food Process Engineering, 42(3), e12988.

Balasubramanian, K. (2006). Molecular orbital basis for yellow curry spice curcumin's prevention of Alzheimer's disease. Journal of Agricultural and Food Chemistry, 54(10), 3512-3520.

Banerjee, I., Mehta, K., Dordick, J., \& Kane, R. (2012). Light-activated porphyrin-based formulations to inactivate bacterial spores. Journal of Applied Microbiology, 113(6), 1461-1467.

Barik, A., \& Priyadarsini, K. I. (2013). Solvent dependent photophysical properties of dimethoxy curcumin. Spectrochimica Acta Part A Molecular and Biomolecular Spectroscopy, 105, 267-272.

Bernabé-Pineda, M., Ramírez-Silva, M. A. T., Romero-Romo, M., González-Vergara, E., \& Rojas-Hernández, A. (2004). Determination of acidity constants of curcumin in aqueous solution and apparent rate constant of its decomposition. Spectrochimica Acta Part A: Molecular and Biomolecular Spectroscopy, 60(5), 10911097.
Bhavya, M., \& Hebbar, H. U. (2019a). Efficacy of blue LED in microbial inactivation: Effect of photosensitization and process parameters. International Journal of Food Microbiology, 290, 296-304.

Bhavya, M., \& Hebbar, H. U. (2019b). Sono-photodynamic inactivation of Escherichia coli and Staphylococcus aureus in orange juice. Ultrasonics Sonochemistry, 57, 108-115.

Bong, P. H. (2000). Spectral and photophysical behaviors of curcumin and curcuminoids. Bulletin of the Korean Chemical Society, 21(1), 81-86.

Bonifácio, D., Martins, C., David, B., Lemos, C., Neves, M., Almeida, A., ... Cunha, Â (2018). Photodynamic inactivation of Listeria innocua biofilms with food-grade photosensitizers: A curcuminrich extract of Curcuma longa vs commercial curcumin. Journal of Applied Microbiology, 125, 282-294.

Bonnett, R. (1995). Photosensitizers of the porphyrin and phthalocyanine series for photodynamic therapy. Chemical Society Reviews, 24(1), 19-33.

Borges, J., Rodrigues, L. C., Reis, R. L., \& Mano, J. F. (2014). Layerby-layer assembly of light-responsive polymeric multilayer systems. Advanced Functional Materials, 24(36), 5624-5648.

Brovko, L. (2010). Photodynamic treatment: A new efficient alternative for surface sanitation. Advances in Food and Nutrition Research, 61, 119-147.

Camm, E., Towers, G. N., \& Mitchell, J. (1975). UV-mediated antibiotic activity of some Compositae species. Phytochemistry, 14(9), 2007 2011.

Cao, R., Xue, C.-H., Liu, Q., \& Xue, Y. (2009). Microbiological, chemical, and sensory assessment of Pacific Oysters (Crassostrea gigas) stored at different temperatures. Czech Journal of Food Sciences, 27(2), 102-108.

Cardoso, D. R., Libardi, S. H., \& Skibsted, L. H. (2012). Riboflavin as a photosensitizer. Effects on human health and food quality. Food \& Function, 3(5), 487-502.

Català, E. C., Sumalla, J. T., \& Ros Salvador, J. (2000). Oxidative stress in bacteria and protein damage by reactive oxygen species. International Microbiology, 3(1), 3-8.

Cebrián, G., Mañas, P., \& Condón, S. (2016). Comparative resistance of bacterial foodborne pathogens to non-thermal technologies for food preservation. Frontiers in Microbiology, 7(734), 1-17.

Chen, B., Huang, J., Li, H., Zeng, Q. H., Wang, J. J., Liu, H., ... Zhao, Y. (2020). Eradication of planktonic Vibrio parahaemolyticus and its sessile biofilm by curcumin-mediated photodynamic inactivation. Food Control, 113, 107181.

Chignell, C. F., Bilskj, P., Reszka, K. J., Motten, A. G., Sik, R. H., \& Dahl, T. A. (1994). Spectral and photochemical properties of curcumin. Photochemistry and Photobiology, 59(3), 295-302.

Choe, E., \& Min, D. B. (2009). Mechanisms of antioxidants in the oxidation of foods. Comprehensive Reviews in Food Science and Food Safety, 8(4), 345-358.

Choi, S., Shin, J.-H., Cheong, Y., Jin, K.-H., \& Park, H.-K. (2013). Structural and biomechanical effects of photooxidative collagen crosslinking with photosensitizer riboflavin and $370 \mathrm{~nm}$ UVA light on human corneoscleral tissues. Microscopy and Microanalysis, 19(5), 1334-1340.

Corrêa, T. Q., Blanco, K. C., Garcia, É. B., Perez, S. M. L., Chianfrone, D. J., Morais, V. S., \& Bagnato, V. S. (2020). Effects of ultraviolet light and curcumin-mediated photodynamic inactivation on microbiological food safety: A study in meat and fruit. Photodiagnosis and Photodynamic Therapy, 30, 101678. 
Cossu, A., Ercan, D., Wang, Q., Peer, W. A., Nitin, N., \& Tikekar, R. V. (2016). Antimicrobial effect of synergistic interaction between UVA light and gallic acid against Escherichia coli $\mathrm{O} 157$ : $\mathrm{H} 7$ in fresh produce wash water and biofilm. Innovative Food Science \& Emerging Technologies, 37, 44-52.

Cozzolino, M., Delcanale, P., Montali, C., Tognolini, M., Giorgio, C., Corrado, M., ... Viappiani, C. (2019). Enhanced photosensitizing properties of protein bound curcumin. Life Sciences, 233, 116710. https://doi.org/10.1016/j.lfs.2019.116710

Darko, E., Heydarizadeh, P., Schoefs, B., \& Sabzalian, M. R. (2014). Photosynthesis under artificial light: The shift in primary and secondary metabolism. Philosophical Transactions of the Royal Society B, 369(1640), 20130243.

D’Souza, C., Yuk, H. G., Khoo, G. H., \& Zhou, W. (2015). Application of light-emitting diodes in food production, postharvest preservation, and microbiological food safety. Comprehensive Reviews in Food Science and Food Safety, 14(6), 719-740.

de Oliveira, E. F., Tikekar, R., \& Nitin, N. (2018). Combination of aerosolized curcumin and UV-A light for the inactivation of bacteria on fresh produce surfaces. Food Research International, 114, 133-139.

de Oliveira, E. F., Tosati, J. V., Tikekar, R. V., Monteiro, A. R., \& Nitin, N. (2018). Antimicrobial activity of curcumin in combination with light against Escherichia coli O157: $\mathrm{H} 7$ and Listeria innocua: Applications for fresh produce sanitation. Postharvest Biology and Technology, 137, 86-94.

Delcanale, P., Montali, C., Rodríguez-Amigo, B., Abbruzzetti, S., Bruno, S., Bianchini, P., ... Viappiani, C. (2016). Zinc-substituted myoglobin is a naturally occurring photo-antimicrobial agent with potential applications in food decontamination. Journal of Agricultural and Food Chemistry, 64(45), 8633-8639.

Delcanale, P., Pennacchietti, F., Maestrini, G., Rodríguez-Amigo, B., Bianchini, P., Diaspro, A., ... Viappiani, C. (2015). Subdiffraction localization of a nanostructured photosensitizer in bacterial cells. Scientific Reports, 5. https://doi.org/10.1038/srep15564.

Demidova, T., \& Hamblin, M. (2004). Photodynamic therapy targeted to pathogens. International Journal of Immunopathology and Pharmacology, 17(3), 245-254.

DeRosa, M. C., \& Crutchley, R. J. (2002). Photosensitized singlet oxygen and its applications. Coordination Chemistry Reviews, 233, 351-371.

Donsì, F., Sessa, M., \& Ferrari, G. (2016). Encapsulation of bioactive compounds. In M. Mishra (Ed.), Handbook of encapsulation and controlled release (pp. 765-799). Boca Raton, FL: CRC Press, Taylor\&Francis Group.

dos Santos, R. F., Campos, B. S., Rego Filho, F. d. A. M. G., de Oliveira Moraes, J., Albuquerque, A. L. I., da Silva, M. C. D., ... de Araujo, M. T. (2019). Photodynamic Inactivation of S. aureus with a water-soluble curcumin salt and an application to cheese decontamination. Photochemical \& Photobiological Sciences, 18(11), 2707 2716. https://doi.org/10.1039/c9pp00196d.

Duse, L., Pinnapireddy, S. R., Strehlow, B., Jedelská, J., \& Bakowsky, U. (2018). Low level LED photodynamic therapy using curcumin loaded tetraether liposomes. European Journal of Pharmaceutics and Biopharmaceutics, 126, 233-241.

Emsley, J. (1984). The composition, structure and hydrogen bonding of the $\beta$-diketones. In M. J. Clarke, J. B. Goodenough, J. A. Ibers, C. K. Jørgensen, D. M. P. Mingos, J. B. Neilands, G. A. Palmer, D. Reinen, P. J. Sadler, R. Weiss, \& R. J. P. Williams (Eds.), Complex chemistry (pp. 147-191). Berlin, Heidelberg: Springer.
Sperandio, F., Huang, Y.-Y., \& Hamblin, M. R. (2013). Antimicrobial photodynamic therapy to kill Gram-negative bacteria. Recent Patents on Anti-infective Drug Discovery, 8(2), 108-120.

Fang, Z., \& Bhandari, B. (2010). Encapsulation of polyphenols-A review. Trends in Food Science \& Technology, 21(10), 510-523.

FAO. (2016). Food and Agriculture Organization of the United Nations, Save Food: Global initiative on food loss and waste reduction, FAO Rome.

Fomina, N., Sankaranarayanan, J., \& Almutairi, A. (2012). Photochemical mechanisms of light-triggered release from nanocarriers. Advanced Drug Delivery Reviews, 64(11), 1005-1020.

Funes, M. D., Caminos, D. A., Alvarez, M. G., Fungo, F., Otero, L. A., \& Durantini, E. N. (2009). Photodynamic properties and photoantimicrobial action of electrochemically generated porphyrin polymeric films. Environmental Science \& Technology, 43(3), 902-908.

Gao, J., \& Matthews, K. R. (2020). Effects of the photosensitizer curcumin in inactivating foodborne pathogens on chicken skin. Food Control, 109, 106959.

Gao, Y., Wu, J., Li, Z., Zhang, X., Lu, N., Xue, C., ... Tang, Q. (2019). Curcumin-mediated photodynamic inactivation (PDI) against DH5 $\alpha$ contaminated in oysters and cellular toxicological evaluation of PDItreated oysters. Photodiagnosis and Photodynamic Therapy, 26, 244251.

Ghatak, C., Rao, V. G., Mandal, S., Ghosh, S., \& Sarkar, N. (2012). An understanding of the modulation of photophysical properties of curcumin inside a micelle formed by an ionic liquid: A new possibility of tunable drug delivery system. The Journal of Physical Chemistry $B, 116(10), 3369-3379$.

Ghate, V., Kumar, A., Kim, M.-J., Bang, W.-S., Zhou, W., \& Yuk, H.-G. (2017). Effect of $460 \mathrm{~nm}$ light emitting diode illumination on survival of Salmonella spp. on fresh-cut pineapples at different irradiances and temperatures. Journal of Food Engineering, 196, 130-138.

Ghate, V., Kumar, A., Zhou, W., \& Yuk, H.-G. (2016). Irradiance and temperature influence the bactericidal effect of 460-nanometer lightemitting diodes on Salmonella in orange juice. Journal of Food Protection, 79(4), 553-560.

Ghate, V. S., Ng, K. S., Zhou, W., Yang, H., Khoo, G. H., Yoon, W.-B., \& Yuk, H.-G. (2013). Antibacterial effect of light emitting diodes of visible wavelengths on selected foodborne pathogens at different illumination temperatures. International Journal of Food Microbiology, 166(3), 399-406.

Ghate, V. S., Zhou, W., \& Yuk, H. G. (2019). Perspectives and trends in the application of photodynamic inactivation for microbiological food safety. Comprehensive Reviews in Food Science and Food Safety, 18(2), 402-424.

Ghosh, R., Mondal, J. A., \& Palit, D. K. (2010). Ultrafast dynamics of the excited states of curcumin in solution. The Journal of Physical Chemistry B, 114(37), 12129-12143.

Giese, A. C. (1980). Photosensitization of organisms, with special reference to natural photosensitizers. In F. Hillenkamp, R. Pratesi \& C. A. Sacchi (Eds.), Lasers in biology and medicine (pp. 299-314). Boston, MA: Springer.

Gilbert, A. R., Alborzi, S., Bastarrachea, L. J., \& Tikekar, R. V. (2018). Photoirradiated caffeic acid as an antimicrobial treatment for fresh produce. FEMS Microbiology Letters, 365(13), fny 132.

Glueck, M., Schamberger, B., Eckl, P., \& Plaetzer, K. (2017). New horizons in microbiological food safety: Photodynamic decontamination based on a curcumin derivative. Photochemical \& Photobiological Sciences, 16(12), 1784-1791. 
Gómez-Estaca, J., Balaguer, M., López-Carballo, G., Gavara, R., \& Hernández-Muñoz, P. (2017). Improving antioxidant and antimicrobial properties of curcumin by means of encapsulation in gelatin through electrohydrodynamic atomization. Food Hydrocolloids, 70, 313-320.

Goswami, T. K., Gadadhar, S., Gole, B., Karande, A. A., \& Chakravarty, A. R. (2013). Photocytotoxicity of copper (II) complexes of curcumin and $\mathrm{N}$-ferrocenylmethyl-L-amino acids. European Journal of Medicinal Chemistry, 63, 800-810.

Gupta, P., Das, K., \& Sharma, M. (2014). Effect of complexing with silica nanoparticles on the phototoxicty of some photosensitisers. Procedia Engineering, 92, 9-18.

Hao, S., Wu, J., Huang, Y., \& Lin, J. (2006). Natural dyes as photosensitizers for dye-sensitized solar cell. Solar Energy, 80(2), 209-214.

Hatcher, H., Planalp, R., Cho, J., Torti, F., \& Torti, S. (2008). Curcumin: From ancient medicine to current clinical trials. Cellular and Molecular Life Sciences, 65(11), 1631-1652.

Haukvik, T., Bruzell, E., Kristensen, S., \& Tønnesen, H. (2009). Photokilling of bacteria by curcumin in different aqueous preparations: Studies on curcumin and curcuminoids XXXVII. Die Pharmazie-An International Journal of Pharmaceutical Sciences, 64(10), 666-673.

Heger, M., van Golen, R. F., Broekgaarden, M., \& Michel, M. C. (2014). The molecular basis for the pharmacokinetics and pharmacodynamics of curcumin and its metabolites in relation to cancer. Pharmacological Reviews, 66(1), 222-307.

Hegge, A. B., Andersen, T., Melvik, J., Bruzell, E., Kristensen, S., \& Tønnesen, H. (2011). Formulation and bacterial phototoxicity of curcumin loaded alginate foams for wound treatment applications: Studies on curcumin and curcuminoides XLII. Journal of Pharmaceutical Sciences, 100(1), 174-185.

Hegge, A. B., Nielsen, T. T., Larsen, K. L., Bruzell, E., \& Tønnesen, H. H. (2012). Impact of curcumin supersaturation in antibacterial photodynamic therapy-Effect of cyclodextrin type and amount: Studies on curcumin and curcuminoides XLV. Journal of Pharmaceutical Sciences, 101(4), 1524-1537.

Hosseinzadeh, R., \& Khorsandi, K. (2017). Methylene blue, curcumin and ion pairing nanoparticles effects on photodynamic therapy of MDA-MB-231 breast cancer cell. Photodiagnosis and Photodynamic Therapy, 18, 284-294.

Hu, J., Lin, S., Tan, B. K., Hamzah, S. S., Lin, Y., Kong, Z., ... Zeng, S. (2018). Photodynamic inactivation of Burkholderia cepacia by curcumin in combination with EDTA. Food Research International, 111, 265-271.

Hu, J., Zhou, F., Lin, Y., Zhou, A., Tan, B. K., Zeng, S., .. Lin, S. (2019) The effects of photodynamically activated curcumin on the preservation of low alum treated ready-to-eat jellyfish. LWT-Food Science and Technology, 115, 108443.

Huang, J., Chen, B., Li, H., Zeng, Q.-H., Wang, J. J., Liu, H., ... Zhao, Y. (2019). Enhanced antibacterial and antibiofilm functions of the curcumin-mediated photodynamic inactivation against Listeria monocytogenes. Food Control, 108, 106886.

Hudson, J., \& Towers, G. (1991). Therapeutic potential of plant photosensitizers. Pharmacology \& Therapeutics, 49(3), 181-222.

Ibrahim, S., Tagami, T., Kishi, T., \& Ozeki, T. (2018). Curcumin marinosomes as promising nano-drug delivery system for lung cancer. International Journal of Pharmaceutics, 540(1-2), 40-49.

Jagannathan, R., Abraham, P. M., \& Poddar, P. (2012). Temperaturedependent spectroscopic evidences of curcumin in aqueous medium
A mechanistic study of its solubility and stability. The Journal of Physical Chemistry B, 116(50), 14533-14540.

Jerca, F. A., Jerca, V. V., \& Stancu, I.-C. (2018). Development and characterization of photoresponsive polymers. In J. Van Hoorick, H. Ottevaere, H. Thienpont, P. Dubruel, \& S. Van Vlierberghe (Eds.), Polymer and photonic materials towards biomedical breakthroughs (pp. 3-47). Cham: Springer.

Jiang, S., Zhu, R., He, X., Wang, J., Wang, M., Qian, Y., \& Wang, S. (2017). Enhanced photocytotoxicity of curcumin delivered by solid lipid nanoparticles. International Journal of Nanomedicine, 12, 167178.

Jiang, Y., Leung, A. W., Hua, H., Rao, X., \& Xu, C. (2014). Photodynamic action of LED-activated curcumin against Staphylococcus aureus involving intracellular ROS increase and membrane damage. International Journal of Photoenergy, 2014, 637601.

Jiménez-Banzo, A., Ragàs, X., Abbruzzetti, S., Viappiani, C., Campanini, B., Flors, C., \& Nonell, S. (2010). Singlet oxygen photosensitisation by GFP mutants: Oxygen accessibility to the chromophore. Photochemical \& Photobiological Sciences, 9(10), 1336-1341.

Jori, G., Camerin, M., Soncin, M., Guidolin, L., \& Coppellotti, O. (2011). Antimicrobial photodynamic therapy: Basic principles. In M. R. Hamblin \& G. Jori (Eds.), Photodynamic Inactivation of Microbial Pathogens: Medical and Environmental Applications, Comprehensive Series in Photochemical \& Photobiological Sciences (Vol. 11, pp. 3-14). Cambridge, UK: Royal Society of Chemistry.

Josewin, S. W., Ghate, V., Kim, M.-J., \& Yuk, H.-G. (2018). Antibacterial effect of $460 \mathrm{~nm}$ light-emitting diode in combination with riboflavin against Listeria monocytogenes on smoked salmon. Food Control, 84, 354-361.

Jovanovic, S. V., Steenken, S., Boone, C. W., \& Simic, M. G. (1999). $\mathrm{H}$-atom transfer is a preferred antioxidant mechanism of curcumin. Journal of the American Chemical Society, 121(41), 9677-9681.

Jucker, B. A., Harms, H., \& Zehnder, A. (1996). Adhesion of the positively charged bacterium Stenotrophomonas (Xanthomonas) maltophilia 70401 to glass and Teflon. Journal of Bacteriology, 178(18), 5472-5479.

Khopde, S. M., Indira Priyadarsini, K., Palit*, D. K., \& Mukherjee, T. (2000). Effect of solvent on the excited-state photophysical properties of curcumin. Photochemistry and Photobiology, 72(5), 625-631.

Kim, M.-J., Bang, W. S., \& Yuk, H.-G. (2017). $405 \pm 5$ nm light emitting diode illumination causes photodynamic inactivation of Salmonella spp. on fresh-cut papaya without deterioration. Food Microbiology, 62, 124-132.

Kolev, T. M., Velcheva, E. A., Stamboliyska, B. A., \& Spiteller, M. (2005). DFT and experimental studies of the structure and vibrational spectra of curcumin. International Journal of Quantum Chemistry, 102(6), 1069-1079.

Konan, Y. N., Gurny, R., \& Allémann, E. (2002). State of the art in the delivery of photosensitizers for photodynamic therapy. Journal of Photochemistry and Photobiology B: Biology, 66(2), 89-106.

Kreitner, M., Wagner, K.-H., Alth, G., Ebermann, R., Foißy, H., \& Elmadfa, I. (2001). Haematoporphyrin-and sodium chlorophyllininduced phototoxicity towards bacteria and yeasts-A new approach for safe foods. Food Control, 12(8), 529-533.

Kudinova, N., \& Berezov, T. (2009). Photodynamic therapy: Search for ideal photosensitizer. Biomeditsinskaia Khimiia, 55(5), 558-569.

Kumar, A., Kaur, G., Kansal, S., Chaudhary, G., \& Mehta, S. (2016). (Cationic+ nonionic) mixed surfactant aggregates for solubilisation 
of curcumin. The Journal of Chemical Thermodynamics, 93, 115122.

Lacey, J. A., \& Phillips, D. (2001). The photosensitisation of Escherichia coli using disulphonated aluminium phthalocyanine. Journal of Photochemistry and Photobiology A: Chemistry, 142(2-3), 145-150.

Lampe, V., \& Milobedzka, J. (1913). Studien über curcumin. Berichte der Deutschen Chemischen Gesellschaft, 46(2), 2235-2240.

Lin, C.-C., Lin, H.-Y., Chen, H.-C., Yu, M.-W., \& Lee, M.-H. (2009). Stability and characterisation of phospholipid-based curcuminencapsulated microemulsions. Food Chemistry, 116(4), 923-928.

Lin, Y., Hu, J., Li, S., Hamzah, S. S., Jiang, H., Zhou, A., ... Lin, S. (2019). Curcumin-based photodynamic sterilization for preservation of fresh-cut Hami Melon. Molecules, 24(13), 2374.

Link, S., \& El-Sayed, M. A. (2000). Shape and size dependence of radiative, non-radiative and photothermal properties of gold nanocrystals. International Reviews in Physical Chemistry, 19(3), 409-453.

Liu, C.-H., Lee, W.-S., \& Wu, W.-C. (2016). Photodynamic inactivation against Pseudomonas aeruginosa by curcumin microemulsions. RSC Advances, 6(67), 63013-63022.

Liu, F., Li, Z., Cao, B., Wu, J., Wang, Y., Xue, Y., ... Tang, Q. J. (2016). The effect of a novel photodynamic activation method mediated by curcumin on oyster shelf life and quality. Food Research International, 87, 204-210.

Lubart, R., Lipovski, A., Nitzan, Y., \& Friedmann, H. (2011). A possible mechanism for the bactericidal effect of visible light. Laser Therapy, 20(1), 17-22.

Luby, B. M., Walsh, C. D., \& Zheng, G. (2018). Advanced photosensitizer activation strategies for smarter photodynamic therapy beacons. Angewandte Chemie International Edition, 58, 2558-2569.

Lukšiene, Ž. (2005). New approach to inactivation of harmful and pathogenic microorganisms by photosensitization. Food Technology and Biotechnology, 43(4), 411-418.

Luksiene, Z., \& Brovko, L. (2013). Antibacterial photosensitizationbased treatment for food safety. Food Engineering Reviews, 5(4), 185-199.

Luksienè, Z., \& Zukauskas, A. (2009). Prospects of photosensitization in control of pathogenic and harmful micro-organisms. Journal of Applied Microbiology, 107(5), 1415-1424.

Lyon, J. P., Moreira, L. M., de Moraes, P. C. G., dos Santos, F. V., \& de Resende, M. A. (2011). Photodynamic therapy for pathogenic fungi. Mycoses, 54(5), e265-e271.

Ma, P., Zeng, Q., Tai, K., He, X., Yao, Y., Hong, X., \& Yuan, F. (2017). Preparation of curcumin-loaded emulsion using high pressure homogenization: Impact of oil phase and concentration on physicochemical stability. LWT-Food Science and Technology, 84, 34-46.

MacEwan, S. R., Callahan, D. J., \& Chilkoti, A. (2010). Stimulusresponsive macromolecules and nanoparticles for cancer drug delivery. Nanomedicine, 5(5), 793-806.

Maclean, M., Macgregor, S., Anderson, J., \& Woolsey, G. (2008). The role of oxygen in the visible-light inactivation of Staphylococcus aureus. Journal of Photochemistry and Photobiology B: Biology, 92(3), 180-184.

Maisch, T., Baier, J., Franz, B., Maier, M., Landthaler, M., Szeimies, R.M., \& Bäumler, W. (2007). The role of singlet oxygen and oxygen concentration in photodynamic inactivation of bacteria. Proceedings of the National Academy of Sciences, 104(17), 7223-7228.

Maisch, T., Szeimies, R.-M., Jori, G., \& Abels, C. (2004). Antibacterial photodynamic therapy in dermatology. Photochemical \& Photobiological Sciences, 3(10), 907-917.
Mandeville, J.-S., Froehlich, E., \& Tajmir-Riahi, H. (2009). Study of curcumin and genistein interactions with human serum albumin. Journal of Pharmaceutical and Biomedical Analysis, 49(2), 468-474.

Masek, A., Chrzescijanska, E., \& Zaborski, M. (2013). Characteristics of curcumin using cyclic voltammetry, UV-vis, fluorescence and thermogravimetric analysis. Electrochimica Acta, 107, 441-447.

McClements, D. J. (2012). Crystals and crystallization in oil-inwater emulsions: Implications for emulsion-based delivery systems. Advances in Colloid and Interface Science, 174, 1-30.

Milobedzka, J., Kostanecki, S. V., \& Lampe, V. (1910). Curcumin. Berichte der Deutschen Chemischen Gesellschaft, 43, 2163 2170.

Moghaddasi, F., Housaindokht, M. R., Darroudi, M., Bozorgmehr, M. R., \& Sadeghi, A. (2018). Synthesis of nano curcumin using black pepper oil by $\mathrm{O} / \mathrm{W}$ nanoemulsion technique and investigation of their biological activities. LWT-Food Science and Technology, 92, 92-100.

Mondal, S., Ghosh, S., \& Moulik, S. P. (2016). Stability of curcumin in different solvent and solution media: UV-visible and steady-state fluorescence spectral study. Journal of Photochemistry and Photobiology B: Biology, 158, 212-218.

Moustapha, A., Pérétout, P., Rainey, N., Sureau, F., Geze, M., Petit, J.-M., ... Petit, P. X. (2015). Curcumin induces crosstalk between autophagy and apoptosis mediated by calcium release from the endoplasmic reticulum, lysosomal destabilization and mitochondrial events. Cell Death Discovery, 1, 15017.

Nabifarkhani, N., Sharifani, M., Daraei Garmakhany, A., Ganji Moghadam, E., \& Shakeri, A. (2015). Effect of nano-composite and Thyme oil (Tymus vulgaris L) coating on fruit quality of sweet cherry (Takdaneh cv) during storage period. Food Science \& Nutrition, 3(4), 349-354.

Nakamura, K., Yamada, Y., Ikai, H., Kanno, T., Sasaki, K., \& Niwano, Y. (2012). Bactericidal action of photoirradiated gallic acid via reactive oxygen species formation. Journal of Agricultural and Food Chemistry, 60(40), 10048-10054.

Nardo, L., Paderno, R., Andreoni, A., Másson, M., Haukvik, T., \& TØnnesen, H. H. (2008). Role of H-bond formation in the photoreactivity of curcumin. Journal of Spectroscopy, 22(2-3), 187-198.

Nikaido, H. (1994). Prevention of drug access to bacterial targets: Permeability barriers and active efflux. Science, 264(5157), 382-388.

Nitzan, Y., \& Ashkenazi, H. (1999). Photoinactivation of Deinococcus radiodurans: An unusual Gram-positive microorganism. Photochemistry and Photobiology, 69(4), 505-510.

Oh, S. W., Gray, P., Dougherty, R., \& Kang, D. H. (2005). Aerosolization as novel sanitizer delivery system to reduce food-borne pathogens. Letters in Applied Microbiology, 41(1), 56-60.

Pan, X., Xie, J., Li, Z., Chen, M., Wang, M., Wang, P.-N., ... Mi, L. (2015). Enhancement of the photokilling effect of aluminum phthalocyanine in photodynamic therapy by conjugating with nitrogendoped TiO2 nanoparticles. Colloids and Surfaces B: Biointerfaces, 130, 292-298.

Paschoal, M. A., Tonon, C. C., Spolidório, D. M., Bagnato, V. S., Giusti, J. S., \& Santos-Pinto, L. (2013). Photodynamic potential of curcumin and blue LED against Streptococcus mutans in a planktonic culture. Photodiagnosis and Photodynamic Therapy, 10(3), 313-319.

Paskeviciute, E., Zudyte, B., \& Luksiene, Z. (2018). Towards better microbial safety of fresh produce: Chlorophyllin-based photosensitization for microbial control of foodborne pathogens on cherry tomatoes. Journal of Photochemistry and Photobiology B: Biology, 182, 130-136. 
Payton, F., Sandusky, P., \& Alworth, W. L. (2007). NMR study of the solution structure of curcumin. Journal of Natural Products, 70(2), 143-146.

Penha, C. B., Bonin, E., da Silva, A. F., Hioka, N., Zanqueta, É. B., Nakamura, T. U., ... \&Mikcha, J. M. G. (2017). Photodynamic inactivation of foodborne and food spoilage bacteria by curcumin. LWT-Food Science and Technology, 76, 198-202.

Pimenta, F. M., Jensen, R. L., Breitenbach, T., Etzerodt, M., \& Ogilby, P. R. (2013). Oxygen-dependent photochemistry and photophysics of "MiniSOG," a protein-encased flavin. Photochemistry and Photobiology, 89(5), 1116-1126.

Preis, E., Baghdan, E., Agel, M. R., Anders, T., Pourasghar, M., Schneider, M., \& Bakowsky, U. (2019). Spray dried curcumin loaded nanoparticles for antimicrobial photodynamic therapy. European Journal of Pharmaceutics and Biopharmaceutics, 142, 531-539.

Priyadarsini, K. I. (2009). Photophysics, photochemistry and photobiology of curcumin: Studies from organic solutions, bio-mimetics and living cells. Journal of Photochemistry and Photobiology C: Photochemistry Reviews, 10(2), 81-95.

PubChem-969516. PubChem Compound Database; CID $=969516$. National Center for Biotechnology Information. Retrieved from https://pubchem.ncbi.nlm.nih.gov/compound/969516

Qian, T., Wang, M., Wang, J., Zhu, R., He, X., Sun, X., ... Wang, S. (2016). Transient spectra study on photo-dynamics of curcumin. Spectrochimica Acta Part A: Molecular and Biomolecular Spectroscopy, 166, 38-43.

Radeglia, R., \& Arrieta, A. (1998). H-1-and C-13 NMR studies of selected vinylogues of dibenzoylmethane (curcumine analogues). Pharmazie, 53(1), 28-32.

Randazzo, W., Aznar, R., \& Sánchez, G. (2016). Curcumin-mediated photodynamic inactivation of norovirus surrogates. Food and Environmental Virology, 8(4), 244-250.

Romanova, N., Brovko, L. Y., Moore, L., Pometun, E., Savitsky, A., Ugarova, N., \& Griffiths, M. (2003). Assessment of photodynamic destruction of Escherichia coli $\mathrm{O} 157$ : $\mathrm{H} 7$ and Listeria monocytogenes by using ATP bioluminescence. Applied and Environmental Microbiology, 69(11), 6393-6398.

Russell, A. (2003). Similarities and differences in the responses of microorganisms to biocides. Journal of Antimicrobial Chemotherapy, 52(5), 750-763.

Setthacheewakul, S., Mahattanadul, S., Phadoongsombut, N., Pichayakorn, W., \& Wiwattanapatapee, R. (2010). Development and evaluation of self-microemulsifying liquid and pellet formulations of curcumin, and absorption studies in rats. European Journal of Pharmaceutics and Biopharmaceutics, 76(3), 475-485.

Shao, L., Hua, B., Sun, J., Li, Q., Yang, J., \& Yu, G. (2017). A cucurbit [7]uril-based supra-amphiphile: Photo-responsive self-assembly and application in controlled release. Tetrahedron Letters, 58(19), 18631867.

Sharma, R., Gescher, A., \& Steward, W. (2005). Curcumin: The story so far. European Journal of Cancer, 41(13), 1955-1968.

Shembekar, V. R., Chen, Y., Carpenter, B. K., \& Hess, G. P. (2005). A protecting group for carboxylic acids that can be photolyzed by visible light. Biochemistry, 44(19), 7107-7114.

Shen, L., \& Ji, H.-F. (2007). Theoretical study on physicochemical properties of curcumin. Spectrochimica Acta Part A: Molecular and Biomolecular Spectroscopy, 67(3-4), 619-623.

Shlar, I., Droby, S., \& Rodov, V. (2018). Antimicrobial coatings on polyethylene terephthalate based on curcumin/cyclodextrin complex embedded in a multilayer polyelectrolyte architecture. Colloids and Surfaces B: Biointerfaces, 164, 379-387.

Singh, P., Choudhury, S., Kulanthaivel, S., Bagchi, D., Banerjee, I., Ahmed, S. A., \& Pal, S. K. (2018). Photo-triggered destabilization of nanoscopic vehicles by dihydroindolizine for enhanced anticancer drug delivery in cervical carcinoma. Colloids and Surfaces B: Biointerfaces, 162, 202-211.

Spikes, J. D. (1989). Photosensitization. In K. C. Smith (Ed.), The science of photobiology, 2nd ed. (pp. 79-110). New York: Plenum Press.

Stannic, Z., \& Grouse, S. (2012). Electrochemical investigation of some biological important compounds correlated to curcumin. Asia Pacific Journal of Life Sciences, 6(2), 153-193.

Sueoka, K., Chikama, T., Pertiwi, Y. D., Ko, J.-A., Kiuchi, Y., Sakaguchi, T., \& Obana, A. (2019). Antifungal efficacy of photodynamic therapy with TONS 504 for pathogenic filamentous fungi. Lasers in Medical Science, 34(4), 743-747.

Sundaryono, A., Nourmamode, A., Gardrat, C., Grelier, S., Bravic, G., Chasseau, D., \& Castellan, A. (2003). Studies on the photochemistry of 1, 7-diphenyl-1, 6-heptadiene-3, 5-dione, a non-phenolic curcuminoid model. Photochemical \& Photobiological Sciences, 2(9), 914 920.

Szymanśki, W., Beierle, J. M., Kistemaker, H. A., Velema, W. A., \& Feringa, B. L. (2013). Reversible photocontrol of biological systems by the incorporation of molecular photoswitches. Chemical Reviews, 113(8), 6114-6178.

Tan, Y. Q., Xiong, H. X., Shi, T. Z., Hua, R. M., Wu, X. W., Cao, H. Q., ... Tang, J. (2013). Photosensitizing effects of nanometer $\mathrm{TiO} 2$ on chlorothalonil photodegradation in aqueous solution and on the surface of pepper. Journal of Agricultural and Food chemistry, 61(21), 5003-5008.

Tao, R., Zhang, F., Tang, Q.-J., Xu, C.-S., Ni, Z.-J., \& Meng, X.H. (2019). Effects of curcumin-based photodynamic treatment on the storage quality of fresh-cut apples. Food Chemistry, 274, 415421.

Tapal, A., \& Tiku, P. K. (2012). Complexation of curcumin with soy protein isolate and its implications on solubility and stability of curcumin. Food Chemistry, 130(4), 960-965.

Temba, B. A., Fletcher, M. T., Fox, G. P., Harvey, J., Okoth, S. A., \& Sultanbawa, Y. (2019). Curcumin-based photosensitization inactivates Aspergillus flavus and reduces aflatoxin B1 in maize kernels. Food Microbiology, 82, 82-88.

Temba, B. A., Fletcher, M. T., Fox, G. P., Harvey, J. J., \& Sultanbawa, Y. (2016). Inactivation of Aspergillus flavus spores by curcuminmediated photosensitization. Food Control, 59, 708-713.

Thompson, D. H., Gerasimov, O. V., Wheeler, J. J., Rui, Y., \& Anderson, V. C. (1996). Triggerable plasmalogen liposomes: Improvement of system efficiency. Biochimica et Biophysica Acta (BBA)Biomembranes, 1279(1), 25-34.

Tiwari, B., \& Mason, T. (2012). Ultrasound processing of fluid foods. In P. J. Cullen, B. K. Tiwari, \& V. Valdramidis (Eds.), Novel thermal and non-thermal technologies for fluid foods, (1st ed., pp. 135-165). San Diego, CA, USA: Elsevier.

Tønnesen, H. H., Karlsen, J., \& van Henegouwen, G. B. (1986). Studies on curcumin and curcuminoids VIII. Photochemical stability of curcumin: Studien über Curcumin und Curcuminoide. VIII. Photochemische Stabilität des Curcumins. Zeitschrift für LebensmittelUntersuchung und Forschung, 183(2), 116-122.

Tønnesen, H. H., Másson, M., \& Loftsson, T. (2002). Studies of curcumin and curcuminoids. XXVII. Cyclodextrin complexation: 
Solubility, chemical and photochemical stability. International Journal of Pharmaceutics, 244(1-2), 127-135.

Tortik, N., Spaeth, A., \& Plaetzer, K. (2014). Photodynamic decontamination of foodstuff from Staphylococcus aureus based on novel formulations of curcumin. Photochemical \& Photobiological Sciences, 13(10), 1402-1409.

Tosati, J. V., de Oliveira, E. F., Oliveira, J. V., Nitin, N., \& Monteiro, A. R. (2018). Light-activated antimicrobial activity of turmeric residue edible coatings against cross-contamination of Listeria innocua on sausages. Food Control, 84, 177-185.

Tuite, E. M., \& Kelly, J. M. (1993). New trends in photobiology: Photochemical interactions of methylene blue and analogues with DNA and other biological substrates. Journal of Photochemistry and Photobiology B: Biology, 21(2-3), 103-124.

Tylkowski, B., Trojanowska, A., Giamberini, M., Tsibranska, I., Nowak, M., Marciniak, Ł., \& Jastrzab, R. (2017). Microencapsulation in food chemistry. Journal of Membrane Science and Research, 3(4), 265271.

Vajragupta, O., Boonchoong, P., Watanabe, H., Tohda, M., Kummasud, N., \& Sumanont, Y. (2003). Manganese complexes of curcumin and its derivatives: Evaluation for the radical scavenging ability and neuroprotective activity. Free Radical Biology and Medicine, 35(12), 1632-1644.

Valverde, J. M., Guillén, F., Martínez-Romero, D., Castillo, S., Serrano, M., \& Valero, D. (2005). Improvement of table grapes quality and safety by the combination of modified atmosphere packaging (MAP) and eugenol, menthol, or thymol. Journal of Agricultural and Food Chemistry, 53(19), 7458-7464.

Vegh, R. B., Solntsev, K. M., Kuimova, M. K., Cho, S., Liang, Y., Loo, B. L. W., ... Bommarius, A. S. (2011). Reactive oxygen species in photochemistry of the red fluorescent protein "Killer Red". Chemical Communications, 47(17), 4887-4889.

Villacorta, R. B., Roque, K. F. J., Tapang, G. A., \& Jacinto, S. D. (2017). Plant extracts as natural photosensitizers in photodynamic therapy: In vitro activity against human mammary adenocarcinoma MCF-7 cells. Asian Pacific Journal of Tropical Biomedicine, 7(4), 358-366.

Wainwright, M., \& Crossley, K. B. (2004). Photosensitising agentsCircumventing resistance and breaking down biofilms: A review. International Biodeterioration \& Biodegradation, 53(2), 119-126.

Wainwright, M., Phoenix, D. A., Nickson, P. B., \& Morton, G. (2002). The use of new methylene blue in Pseudomonas aeruginosa biofilm destruction. Biofouling, 18(4), 247-249.
Wang, C., Liu, Z., Xu, G., Yin, B., \& Yao, P. (2016). BSA-dextran emulsion for protection and oral delivery of curcumin. Food Hydrocolloids, 61, 11-19.

Wikene, K. O., Bruzell, E., \& Tønnesen, H. H. (2015). Characterization and antimicrobial phototoxicity of curcumin dissolved in natural deep eutectic solvents. European Journal of Pharmaceutical Sciences, 80 , 26-32.

Wikene, K. O., Hegge, A. B., Bruzell, E., \& Tønnesen, H. H. (2015). Formulation and characterization of lyophilized curcumin solid dispersions for antimicrobial photodynamic therapy (aPDT): Studies on curcumin and curcuminoids LII. Drug Development and Industrial Pharmacy, 41(6), 969-977.

Winter, S., Tortik, N., Kubin, A., Krammer, B., \& Plaetzer, K. (2013). Back to the roots: Photodynamic inactivation of bacteria based on water-soluble curcumin bound to polyvinylpyrrolidone as a photosensitizer. Photochemical \& Photobiological Sciences, 12(10), 1795-1802.

Wood, O. B., \& Bruhn, C. M. (2000). Position of the American Dietetic Association: Food irradiation. Journal of the Academy of Nutrition and Dietetics, 100(2), 246.

Wu, J., Hou, W., Cao, B., Zuo, T., Xue, C., Leung, A. W., ... Tang, Q.-J. (2015). Virucidal efficacy of treatment with photodynamically activated curcumin on murine norovirus bio-accumulated in oysters. Photodiagnosis and Photodynamic Therapy, 12(3), 385-392.

Wu, J., Mou, H., Xue, C., Leung, A. W., Xu, C., \& Tang, Q.-J. (2016). Photodynamic effect of curcumin on Vibrio parahaemolyticus. Photodiagnosis and Photodynamic Therapy, 15, 34-39.

Yip, L., Hudson, J., Gruszecka-Kowalik, E., Zalkow, L., \& Towers, G. N. (1996). Antiviral activity of a derivative of the photosensitive compound hypericin. Phytomedicine, 3(2), 185-190.

How to cite this article: Damyeh MS, Mereddy R, Netzel ME, Sultanbawa Y. An insight into curcumin-based photosensitization as a promising and green food preservation technology. Compr Rev Food Sci Food Saf. 2020;19:1727-1759. https://doi.org/10.1111/1541-4337.12583 